Provided for non-commercial research and education use. Not for reproduction, distribution or commercial use.

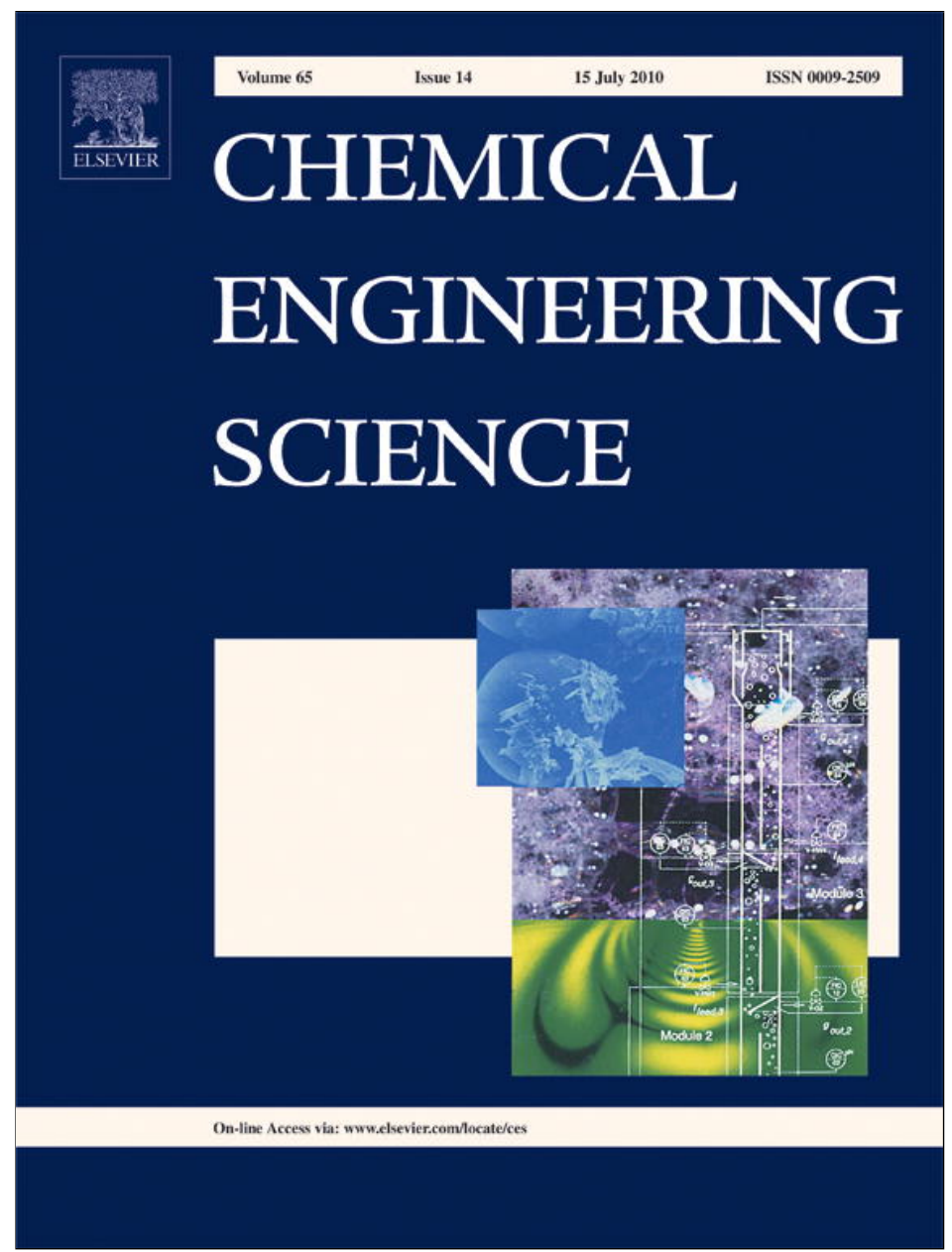

This article appeared in a journal published by Elsevier. The attached copy is furnished to the author for internal non-commercial research and education use, including for instruction at the authors institution and sharing with colleagues.

Other uses, including reproduction and distribution, or selling or licensing copies, or posting to personal, institutional or third party websites are prohibited.

In most cases authors are permitted to post their version of the article (e.g. in Word or Tex form) to their personal website or institutional repository. Authors requiring further information regarding Elsevier's archiving and manuscript policies are encouraged to visit:

http://www.elsevier.com/copyright 


\title{
Adaptive type-2 fuzzy logic control of a bioreactor
}

\author{
Mosè Galluzzo*, Bartolomeo Cosenza \\ Dipartimento di Ingegneria Chimica dei Processi e dei Materiali, Università di Palermo, Viale delle Scienze, 90128 Palermo, Italy
}

\section{A R T I C L E I N F O}

\section{Article history:}

Received 8 September 2009

Received in revised form

25 February 2010

Accepted 16 April 2010

Available online 27 April 2010

Keywords:

Process control

Adaptive control

Type-2 fuzzy logic control

Stability

Nonlinear dynamics

Bioreactor

\begin{abstract}
A B S T R A C T
Two adaptive type-2 fuzzy logic controllers with minimum number of rules are developed and compared by simulation for control of a bioreactor in which aerobic alcoholic fermentation for the growth of Saccharomyces cerevisiae takes place. The bioreactor model is characterized by nonlinearity and parameter uncertainty. The first adaptive fuzzy controller is a type-2 fuzzy-neuro-predictive controller (T2FNPC) that combines the capability of type-2 fuzzy logic to handle uncertainties, with the ability of predictive control to predict future plant performance making use of a neural network model of the nonlinear system. The second adaptive fuzzy controller is instead a self-tuning type- 2 PI controller, where the output scaling factor is adjusted online by fuzzy rules according to the current trend of the controlled process. The performance of a type- 2 fuzzy logic controller with 49 rules is used as reference.
\end{abstract}

(c) 2010 Elsevier Ltd. All rights reserved.

\section{Introduction}

It is well known that traditional controllers cannot achieve good performances when the process to be controlled is characterized by high nonlinearities and parameter uncertainties. In fact a PID controller can be tuned to be effective at certain conditions, but it is not very robust and a change in the value of some system parameters may also destabilize the whole control system. For this reason nonlinear controllers like fuzzy controllers are used to control such systems because they are more robust than traditional controllers and can handle changes in system parameters as well. Fuzzy logic systems come in two types: type 1 and type 2 (Mendel, 2002; Zadeh, 1975). It has been demonstrated that a type- 1 fuzzy logic controller (FLC) may find difficulty in minimizing the negative effects of all uncertainties that may be present in a control system. Galluzzo et al. (2008), Hagras (2007), Sepulveda et al. (2007) and Wu and Tan $(2004,2006)$ have shown the superiority of type-2 FLCs over their type- 1 counter-parts. Type- 2 FLCs in fact can handle uncertainties more efficiently than type- 1 FLCs because they are characterized by a larger number of parameters and more design degrees of freedom. Applications in the field of process control deal with plant control (Castillo et al., 2005), marine diesel engines control (Lynch et al., 2006), liquid level

\footnotetext{
* Corresponding author.

E-mail addresses: galluzzo@unipa.it (M. Galluzzo), b.cosenza@dicpm.unipa.it (B. Cosenza).
}

process control (Wu and Tan, 2006), control architecture for autonomous mobile robots (Hagras, 2004; Martinez et al., 2008), control for vehicle active suspensions (Cao et al., 2008) and biochemical reactor (Galluzzo et al., 2008; Galluzzo and Cosenza, 2009).

The process that is considered in this work is a biochemical reactor for aerobic growth of Saccharomyces using glucose and ethanol as substrates. A dynamic analysis of the process model showed that the region of dilution rate $D$ within which multiple steady states occur depends on feed concentration and kinetic parameters as well. Consequently, multiple steady states may occur over a relatively large range of dilution rates, changing the inlet concentration or kinetic parameter values. The objective of the control system is to properly modify the dynamic behaviour of the system, taking into account all possible disturbances and uncertainties, preventing it from reaching some steady states that, although stable, could be unacceptable for operation of the process.

In order to improve the performance of the control system, two different adaptive algorithms have been introduced in type-2 FLCs with the objective of making the control system more robust and reactive to uncertainties and disturbances. Another intended objective is to greatly decrease the number of controller rules and consequently to reduce computational load.

In Section 2 type-2 fuzzy sets and type-2 fuzzy logic systems (FLSs) are briefly described; Section 3 describes the process, its nonlinear state space model and the control problems that may arise; Section 4 describes characteristics of the designed fuzzy controllers; in Section 5 simulation results are discussed; the conclusion follows in Section 6. 


\section{Type-2 fuzzy logic}

\subsection{Type-2 fuzzy sets}

A fuzzy set $\tilde{A}$ is characterized by a type- 2 membership function $\mu_{\tilde{A}}(x, u)$, where $x \in X, u \in J_{x} \subseteq[0,1]$, and is defined as

$\tilde{A}=\int_{x \in X} \int_{u \in J_{x}} \mu_{\tilde{A}}(x, u) /(x, u), \quad J \subseteq[0,1]$

In (1) $0 \leq \mu_{\tilde{A}}(x, u) \leq 1$ is the secondary grade while the primary membership of $x$ represents the domain of the secondary membership function.

Type-2 fuzzy set operations require a prohibitive computation load so that, at present, only a particular sub-case of type- 2 fuzzy sets is used in applications - the interval type- 2 fuzzy sets. Also in this paper only interval type-2 fuzzy sets are considered. An interval type-2 fuzzy set $\tilde{A}_{I}$ is defined as follows:

$\tilde{A}_{I}=\int_{x \in X} \int_{u \in J_{x} \subseteq[0,1]} 1 /(x, u)=\int_{x \in X}\left[\int_{u \in J_{x} \subseteq[0,1]} 1 / u\right] / x$

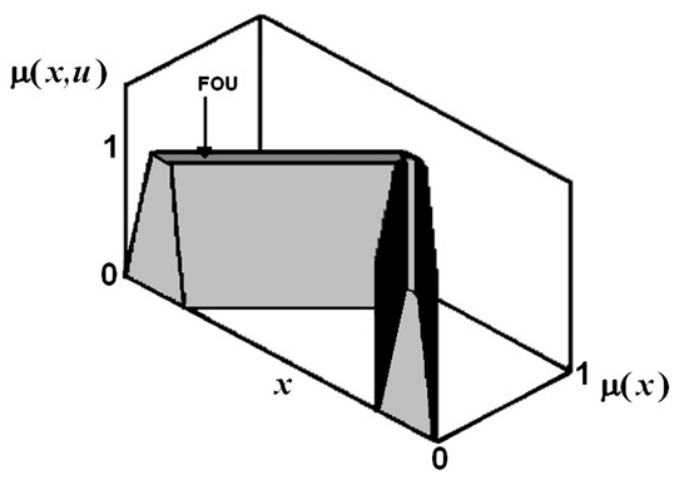

Fig. 1. Interval type-2 fuzzy membership function.

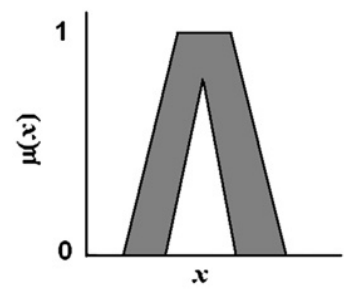

Fig. 2. FOU for a triangular membership function (shaded region).
The main characteristic of the interval set is that its secondary grade is [0,1] (Fig. 1). Uncertainty is an inherent part of any control system but type-2 fuzzy logic in particular shows all its potential in those environments that are full of uncertainties. Type-2 fuzzy sets have a primary membership that is a fuzzy set itself. Therefore, it is possible to define for them a bounded region called the footprint of uncertainty (FOU; Karnik and Mendel, 2000a; Mendel and Liang, 1999).

All uncertainties present in a system can be taken into account by a suitable use of FOU (Fig. 2) and their negative effects can consequently be minimized as well. The FOU represents the entire interval type-2 fuzzy set and its shading denotes interval sets for secondary membership functions.

\subsection{Type-2 fuzzy logic}

As in type-1 fuzzy logic systems, type-2 fuzzy logic systems contain four components as well: a rules base, a fuzzifier, an inference engine and an output processor.

The last component represents the main difference between type-2 and type-1 fuzzy logic systems (Mendel and Liang, 1999; Karnik and Mendel, 1998). For a type-1 FLS it is just a defuzzifier, while, for a type-2 FLS it consists of two sub-components: the first maps a type- 2 fuzzy set to a type- 1 fuzzy set, while the second sub-component is a normal defuzzifier that transforms a fuzzy output to a crisp output (Fig. 3).

The centre of sets type reducer is one of the most used typereduction method and can be expressed as

$$
\begin{aligned}
Y_{\cos }(x) & =\left[y_{1}, y_{\mathrm{r}}\right] \\
& =\int_{y^{1} \in\left[y_{1}^{1}, y_{\mathrm{r}}^{1}\right]} \cdots \int_{y^{M} \in\left[y_{1}^{M}, y_{\mathrm{r}}^{M}\right]} \int_{f^{1} \in\left[\left[_{-}^{1}, \bar{f}^{1}\right]\right.} \cdots \int_{f^{M} \in\left[f_{-}^{M}, \bar{f}^{M}\right]} 1 /\left(\frac{\sum_{i=1}^{M} f^{i} y^{i}}{\sum_{i=1}^{M} f^{i}}\right)
\end{aligned}
$$

In (3) $Y_{\cos }(x)$ is an interval set, $y_{1}$ and $y_{\mathrm{r}}$ are its end points, $\left[f^{i}, \bar{f}^{i}\right]$ and $\left[y_{1}^{i}, y_{\mathrm{r}}^{i}\right]$ are, respectively, the interval firing level of the $i$ th rule and centroid of the consequent interval type- 2 set.

Eq. (3) is solved using the Karnik-Mendel iterative method (Karnik and Mendel, 2000b) with interval type-2 fuzzy sets. The defuzzified output is calculated as the average of $y_{1}$ and $y_{\mathrm{r}}$ :

$$
y(x)=\frac{y_{1}+y_{\mathrm{r}}}{2}
$$

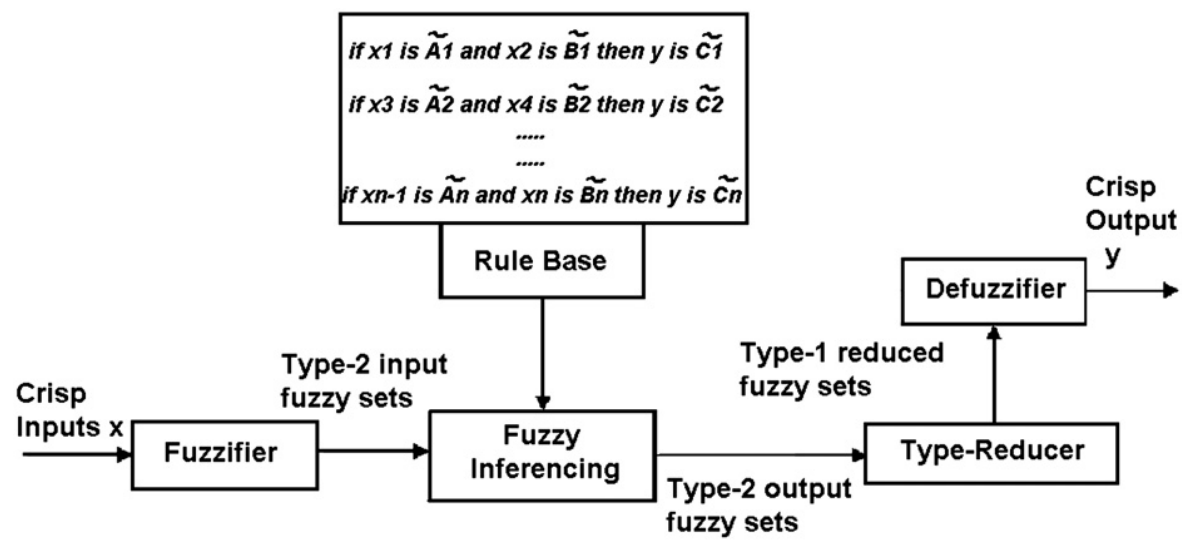

Fig. 3. Type-2 fuzzy logic system structure. 


\section{Model dynamics analysis}

For the control simulation study presented in this paper, the model of a bioreactor for aerobic growth of Saccharomyces cerevisiae on a glucose limited medium, given by Lei et al. (2001), was used as the system to be controlled. S. cerevisiae is commonly used as baker's yeast. The yeast bioreactor model was developed using experimental results of the pyruvate metabolism around the critical dilution rate and tested by Lei on steady-state and dynamic experiments in glucose limited cultures.

\subsection{Nonlinear state-space model}

The state-space model of the isothermal nonlinear continuous bioreactor is reported in Eqs. (5)-(23). The Michaelis-Menten kinetics with a first order dependency on active biomass $X_{\mathrm{a}}$ is assumed. Volume $V$ and all physical-chemical properties are assumed constant. For a more detailed description of each reaction see Lei et al. (2001).

$\frac{d s_{\text {glu }}}{d t}=-\left(r_{1}+r_{7}\right) x+\left(S_{\mathrm{f}}-S_{\text {glu }}\right) D$

$\frac{d s_{\mathrm{pyr}}}{d t}=\left(0.978 r_{1}-r_{2}-r_{3}\right) x-s_{\mathrm{pyr}} D$

$\frac{d s_{\text {acetald }}}{d t}=\left(0.5 r_{3}-r_{4}-r_{6}\right) x-s_{\text {acetald }} D$

$\frac{d s_{\text {acetate }}}{d t}=\left(1.363 r_{4}-r_{5}-r_{8}\right) x-s_{\text {acetate }} D$

$\frac{d s_{\mathrm{EtOH}}}{d t}=1.045 r_{6} x-s_{\mathrm{EtOH}} D$

$\frac{d x}{d t}=\left(0.732 r_{7}+0.619 r_{8}-D\right) x$

$\frac{d X_{\mathrm{a}}}{d t}=0.732 r_{7}+0.619 r_{8}-r_{9}-r_{10}-\left(0.732 r_{7}+0.619 r_{8}\right) X_{\mathrm{a}}$

$\frac{d X_{\text {Acdh }}}{d t}=r_{9}-r_{11}-\left(0.732 r_{7}+0.619 r_{8}\right) X_{\text {Acdh }}$

$r_{1}=k_{11} \frac{s_{\text {glu }}}{s_{\text {glu }}+K_{11}} X_{\mathrm{a}}+k_{1 \mathrm{~h}} \frac{s_{\text {glu }}}{s_{\text {glu }}+K_{1 \mathrm{~h}}} X_{\mathrm{a}}$

$+k_{1 \mathrm{e}} \frac{s_{\text {glu }}}{s_{\text {glu }}\left(K_{1 \mathrm{t}} S_{\text {acetald }}+1\right)+K_{1 \mathrm{e}}} S_{\text {acetald }} X_{\mathrm{a}}$

$r_{2}=k_{2} \frac{s_{\mathrm{pyr}}}{s_{\mathrm{pyr}}+K_{2}} \frac{1}{s_{\mathrm{glu}} K_{1 \mathrm{t}}+1} X_{\mathrm{a}}$

$r_{3}=k_{3} \frac{s_{\mathrm{pyr}}^{4}}{s_{\mathrm{pyr}}^{4}+K_{3}} X_{\mathrm{a}}$

$r_{4}=k_{4} \frac{s_{\text {acetald }}}{s_{\text {acetald }}+K_{4}} X_{\mathrm{a}} X_{\text {Acdh }}$

$r_{5}=\left(k_{5} \frac{s_{\text {acetate }}}{s_{\text {acetate }}+K_{5}}+k_{5 e} \frac{s_{\text {acetate }}}{s_{\text {acetate }}+K_{5 \mathrm{e}}} \frac{1}{s_{\text {glu }} K_{5 \mathrm{t}}+1}\right) X_{\mathrm{a}}$

$r_{6}=k_{6} \frac{s_{\text {acetald }}-k_{6 r} s_{\mathrm{EtOH}}}{s_{\text {acetald }}+K_{6}+K_{6 \mathrm{e}} s_{\mathrm{EtOH}}} X_{\mathrm{a}}$

$r_{7}=k_{7} \frac{s_{\text {glu }}}{s_{\text {glu }}+K_{7}} X_{\mathrm{a}}$

$r_{8}=k_{8} \frac{s_{\text {acetate }}}{s_{\text {acetate }}+K_{5 e}} \frac{1}{s_{\text {glu }} K_{5 \mathrm{t}}+1} X_{\mathrm{a}}$
Table 1

Parameters of the fermentation reactor.

\begin{tabular}{ll}
\hline Parameter & Value \\
\hline$k_{1 \mathrm{~h}}$ & 0.584 \\
$K_{1 \mathrm{~h}}$ & 0.0116 \\
$k_{11}$ & 1.43 \\
$K_{11}$ & 0.94 \\
$k_{1 \mathrm{e}}$ & 47.1 \\
$K_{1 \mathrm{e}}$ & 0.12 \\
$K_{1 \mathrm{t}}$ & 14.2 \\
$k_{2}$ & 0.501 \\
$K_{2}$ & $2 \times 10-5$ \\
$K_{2 t}$ & 0.101 \\
$k_{2}$ & 5.81 \\
$K_{3}$ & $5 \times 10-7$ \\
$k_{4}$ & 4.80 \\
$K_{4}$ & $2.64 \times 10-4$ \\
$k_{5}$ & 0.0104 \\
$K_{5}$ & 0.0102 \\
$k_{5 \mathrm{e}}$ & 0.775 \\
$K_{5 \mathrm{e}}$ & 0.1 \\
$K_{5 \mathrm{t}}$ & 440 \\
$k_{6}$ & 2.82 \\
$K_{6}$ & 0.034 \\
$k_{6 \mathrm{r}}$ & 0.0125 \\
$K_{6 \mathrm{e}}$ & 0.057 \\
$k_{7}$ & 1.203 \\
$K_{7}$ & 0.0101 \\
$k_{8}$ & 0.589 \\
$k_{9}$ & 0.008 \\
$K_{9}$ & $1 \times 10-6$ \\
$k_{9 \mathrm{e}}$ & 0.0751 \\
$K_{9 \mathrm{e}}$ & 13 \\
$K_{9 \mathrm{t}}$ & 25 \\
$k_{9 \mathrm{c}}$ & $3.99 \times 10-3$ \\
$k_{10}$ & 0.392 \\
$K_{10}$ & $2.3 \times 10-3$ \\
$k_{10 \mathrm{e}}$ & $3.39 \times 10-3$ \\
$K_{10 \mathrm{e}}$ & $1.8 \times 10-3$ \\
$k_{11}$ & 0.02 \\
\hline & \\
\hline & \\
\hline
\end{tabular}

$r_{9}=\left(k_{9} \frac{s_{\text {glu }}}{s_{\text {glu }}+K_{9}}+k_{9 \mathrm{e}} \frac{s_{\mathrm{EtOH}}}{s_{\mathrm{EtOH}}+K_{9 \mathrm{e}}}\right) \frac{1}{s_{\text {glu }} K_{9 \mathrm{t}}+1} X_{\mathrm{a}}+k_{9 \mathrm{c}} \frac{s_{\mathrm{glu}}}{s_{\mathrm{glu}}+K_{9}} X_{\mathrm{a}}$

$r_{10}=\left(k_{10} \frac{s_{\mathrm{glu}}}{s_{\mathrm{glu}}+K_{10}}+k_{10 \mathrm{e}} \frac{s_{\mathrm{EtOH}}}{s_{\mathrm{EtOH}}+K_{10 \mathrm{e}}}\right) X_{\mathrm{a}}$

$r_{11}=k_{11} X_{\text {Acdh }}$

Values of the parameters used in the model are given in Table 1.

\subsection{Control objective and strategy}

Different controllers have been proposed for bioreactor control. Fredriksson (2001) developed a robust PID controller with the purpose of keeping specific glucose uptake rate below the critical specific uptake rate, in order to avoid over-flow metabolism. A predictive control of fed-batch yeast growth controlling ethanol production was instead developed by Preuß et al. (2000). In this study the control of glucose concentration inside the bioreactor using dilution rate $D$ as a manipulation variable was chosen. The growth behaviour of $S$. cerevisiae is strongly influenced by glucose concentration as glucose is used as the carbon and energy source. Furthermore an efficient control of glucose concentration is important to avoid the Crabtree effect (Postma et al., 1989). The control system objective is to keep glucose concentration to the desired set-point value, reducing the effects of disturbances represented by changes of substrate feed concentration $S_{\mathrm{f}}$ and of some system kinetic parameters. The 
a

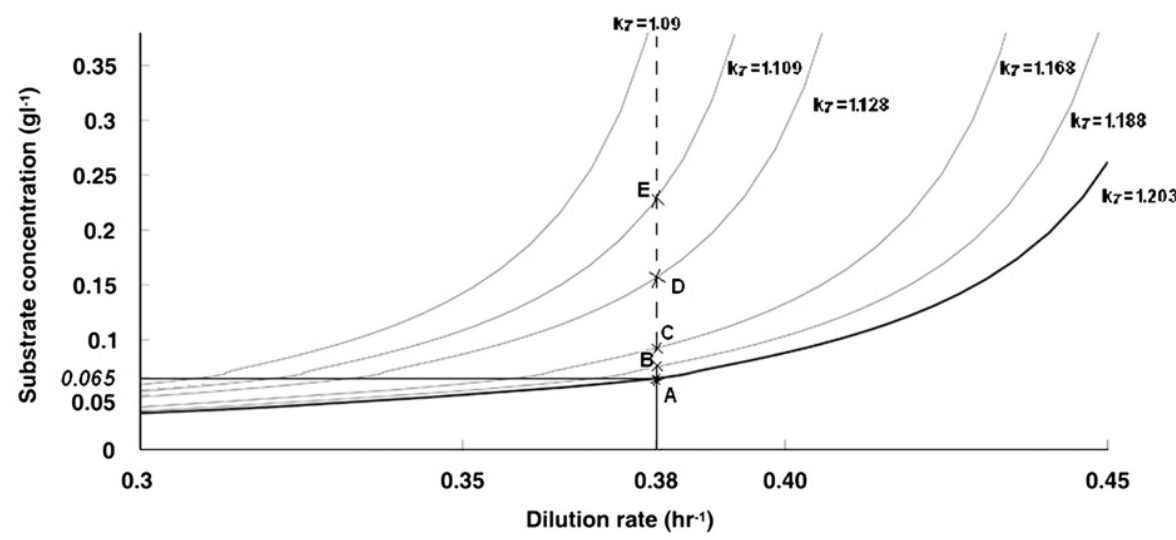

b

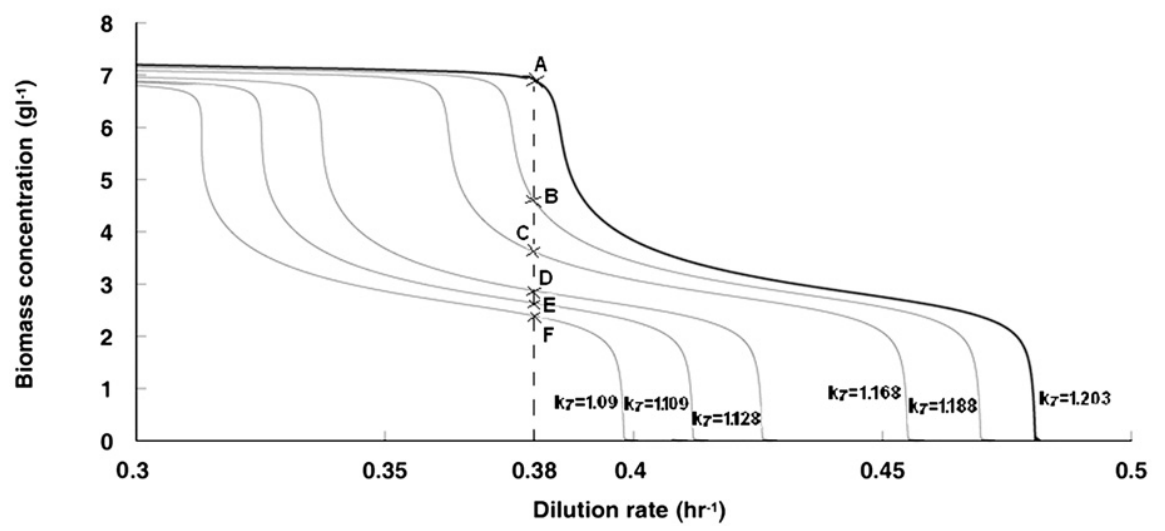

Fig. 4. Continuity diagrams: substrate concentration (a) and biomass concentration (b) vs dilution rate, for $k_{7}$ parameter value changing from 1.203 to 1.09.

Table 2

Fuzzy control rules.

\begin{tabular}{llllllll}
\hline $\boldsymbol{e} /$ int $\boldsymbol{e}$ & NB & NM & NS & ZE & PS & PM & PB \\
\hline NB & NB & NB & NB & NM & NS & NS & ZE \\
NM & NB & NM & NM & NM & NS & ZE & PS \\
NS & NB & NM & NS & NS & ZE & PS & PM \\
ZE & NB & NM & NS & ZE & PS & PM & PB \\
PS & NM & NS & ZE & PS & PS & PM & PB \\
PM & NS & ZE & PS & PM & PM & PM & PB \\
PB & ZE & PS & PS & PM & PB & PB & PB \\
\hline
\end{tabular}

selected working point of the bioreactor (without control) is located in the low branch of the continuity diagram of Fig. 4(a), where a high conversion can be obtained with a value of substrate concentration equal to $0.065 \mathrm{gl}^{-1}$. From the continuity diagrams shown in the Fig. 4(a) and (b) it can be seen (curve with pronounced stroke) that for this substrate concentration value, the corresponding equilibrium values of dilution rate and biomass concentration are $0.38 \mathrm{~h}^{-1}$ and $6.9 \mathrm{gl}^{-1}$, respectively (point $\mathrm{A}$ in Fig. 4(a) and (b)). Let us suppose now that the value of kinetic parameter $k_{7}$ changes from the normal value 1.203 (Table 2) to 1.09. In Fig. 4 continuity diagrams for different intermediate values between these extreme values are reported. For $k_{7}=1.188$ in correspondence with the dilution rate value of $0.38 \mathrm{~h}^{-1}$ the new equilibrium value reached by substrate concentration (without control) is higher than $0.065 \mathrm{gl}^{-1}$ (point B). This new operative condition, although stable, is characterized by lower conversion of biomass as shown in the continuity diagram of biomass concentration vs dilution rate in Fig. 4(b).
For $k_{7}=1.09$ in correspondence with $D=0.38 \mathrm{~h}^{-1}$, the new equilibrium value reached by substrate concentration is much higher than $0.065 \mathrm{gl}^{-1}$ and it is not reported in Fig. 4(a) due to scale problem. This new steady state is therefore characterized by a very low conversion of biomass as shown by point $\mathrm{F}$ in Fig. 4(b). Note that a small change ( $\cong 9 \%$ ) of a particular kinetic parameter could cause a large decrease in biomass product ( $\cong 300 \%$ ).

The objective of the control system is therefore to effectively manipulate the control variable $D$ to keep glucose concentration to the constant value of $0.065 \mathrm{gl}^{-1}$ in spite of kinetic parameter variations, forcing therefore the system to stay in the lower branches of the new continuity diagrams. This applies also to disturbances in feed substrate concentration.

In Fig. 5(a) and (b) the effects of $k_{7}$ change on glucose concentration for the uncontrolled system are shown. The $k_{7}$ change consists of a linear variation from the initial value of 1.203 at $t=0$ to 0.953 in $50 \mathrm{~h}$. Also a change in feed substrate concentration obviously modifies the steady state of the bioreactor with undesirable effects on biomass concentration.

In Fig. 6(a) and (b) the effects of a disturbance in substrate feed concentration on reactor substrate and biomass concentrations for the uncontrolled bioreactor are shown. Changes of glucose and biomass concentrations for a step in $S_{\mathrm{f}}$ from an initial value of 15 to $14\left(\mathrm{~g}^{-1}\right)$ at $t=20 \mathrm{~h}$ are not so significant if compared with the previous simulation result, but the negative effects on biomass concentration remain.

The analysis of full dynamic behaviour of the process leads to the conclusion that the control of reactor temperature acting on cooling flow rate cannot be carried out by a simple traditional PID controller owing to the strong nonlinearity of the process for 
a

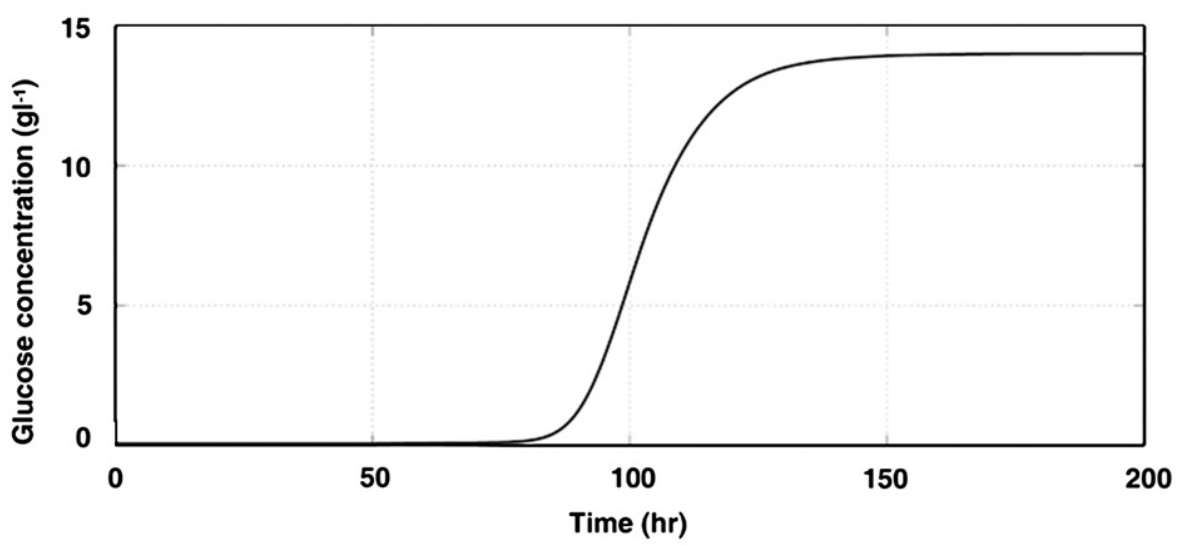

b

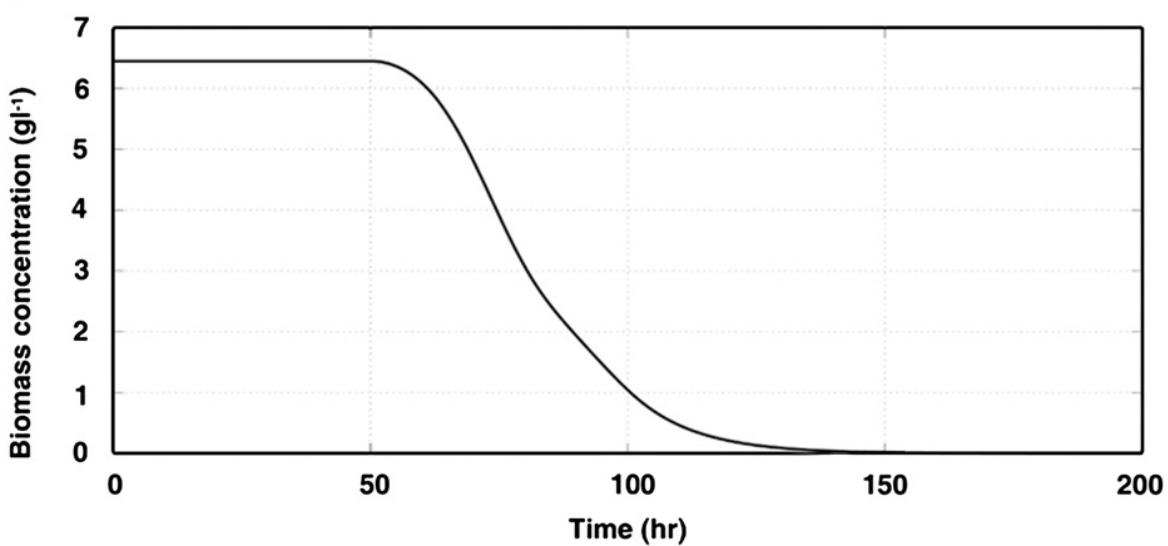

Fig. 5. Glucose concentration (a) and biomass concentration (b) for a linear change of $k_{7}$ from the initial value of 1.203 to 0.953 in $50 \mathrm{~h}$.

disturbance and parameter change as illustrated by previous considerations.

Some preliminary simulations carried out using a PID controller confirmed the above conclusion and directed us, on the basis of previous successful results with other nonlinear processes with parameter uncertainty (Galluzzo et al., 2008; Galluzzo and Cosenza, 2009), to the use of a type-2 fuzzy controller or as an alternative to the development and experimentation of two type-2 fuzzy adaptive controllers. These are based on different approaches: one is a hybrid neuro-predictive controller while the second has a self-tuning structure already used with type- 1 fuzzy controllers for the control of nonlinear systems with bifurcations (Montana Lampo et al., 2002).

\section{Fuzzy controller structure}

\subsection{Type-2 fuzzy controller}

As previously said, three type-2 fuzzy controllers were designed, two of which are adaptive. The type-2 fuzzy controller T2FC with 49 rules was designed with two inputs, error $(e)$, integral of error (inte), one output (control variable) and a zeroorder Sugeno inference method (Sugeno, 1985). For each input variable, seven Gaussian membership functions were chosen. Fig. 7 shows the fuzzy sets for the first and second inputs and Table 2 shows instead the rule base ( 49 rules) chosen for the simple type-2 fuzzy controller.

For the control of processes with time varying parameters the adaptive control represents a better alternative in terms of efficiency and in terms of computational load. Therefore, although the controller with a large number of rules resulted in a robust controller in the simulation results previously reported, for this particular system, in which many parameters are time varying, two different adaptive fuzzy controllers were designed.

\subsection{Type-2 fuzzy neuro-predictive controller}

The first adaptive controller has a hybrid type-2 fuzzy predictive-neural-control structure (T2FNPC). The part of the controller regarding the predictive control action uses the receding horizon technique and the part of the controller regarding the neural network provides, after a training stage, the model of the system from which prediction of plant response is obtained.

The prediction is carried out by a numerical optimization program that determines the control signal that minimizes a performance criterion over a specified horizon as follows:

$J=\sum_{j=N_{1}}^{N_{2}}\left(y_{\mathrm{r}}(t+j)-y_{\mathrm{m}}(t+j)\right)^{2}+\rho \sum_{j=1}^{N_{u}}\left(u^{\prime \prime \prime}(t+j-1)-u^{\prime \prime \prime}(t+j-2)\right)$

The tracking error and incremental control action are evaluated over the horizons defined by $N_{1}, N_{2}$ and $N_{u} ; y_{\mathrm{r}}$ and $y_{\mathrm{m}}$ are the desired response and the neural network model response, respectively; $\rho$ is the control weighting factor.

The whole adaptive mechanism is therefore divided into two parts: the neural network plant model and the optimization block (Fig. 8). The optimization block determines the value of $u^{\prime \prime}{ }_{t}$ that minimizes $J$ and then the optimal value $u^{\prime \prime}$ multiplied by a constant $K_{1}$ is sent to the product operator. The measured output 
a

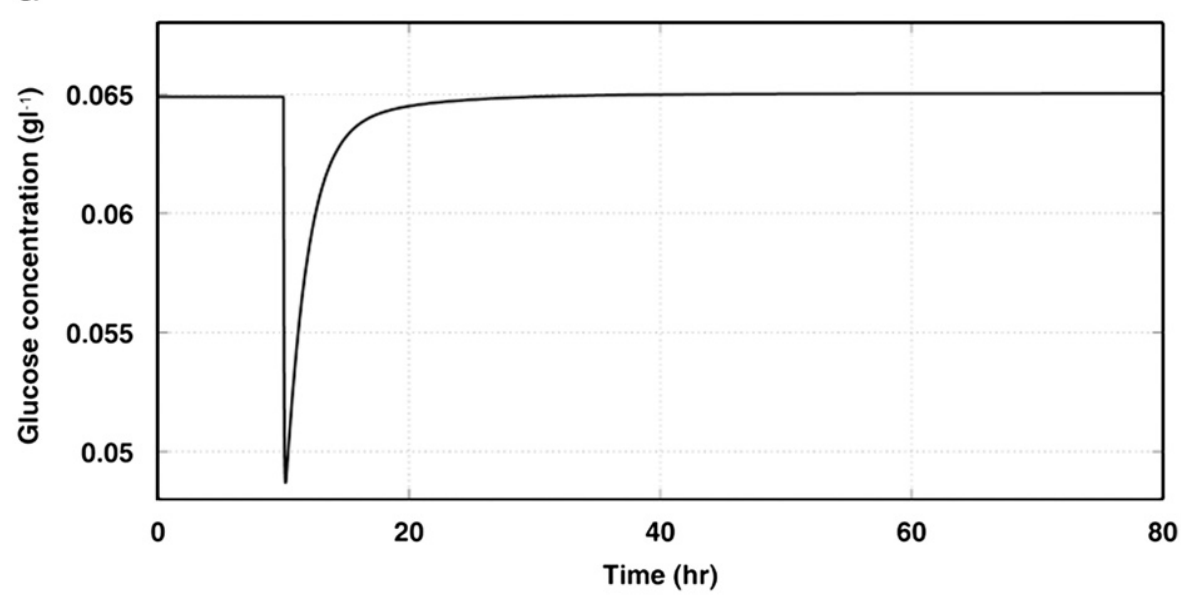

b

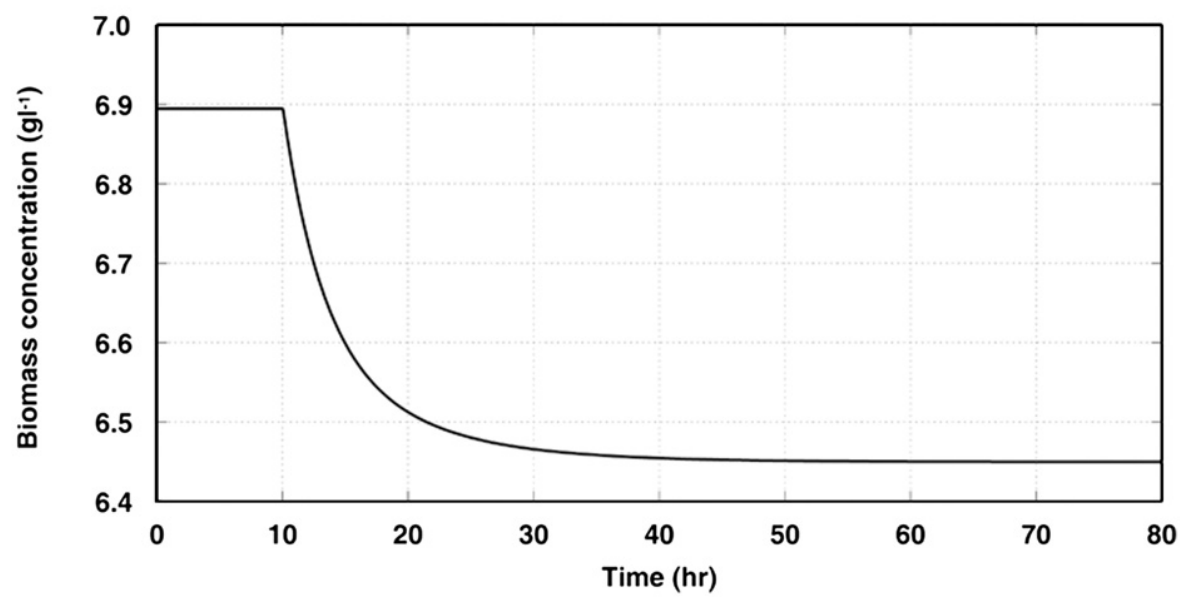

Fig. 6. Glucose concentration (a) and biomass concentration (b) for a step change of $S_{\mathrm{f}}$ from an initial value of 15 to 14 ( $\mathrm{gl} \mathrm{l}^{-1}$ ) at $t=20 \mathrm{~h}$.

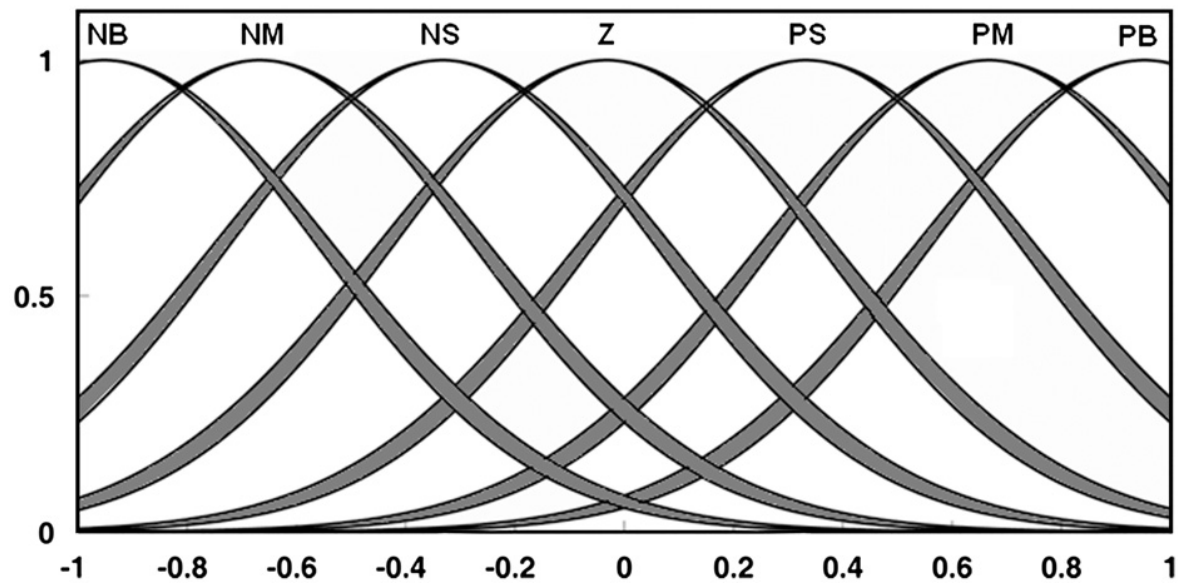

Fig. 7. Fuzzy sets (error and integral of error) for the type-2 fuzzy controller with 49 rules.

of the control system, substrate concentration, constitutes also the input signal of the predictive-neural network controller.

The type- 2 feedback fuzzy controller is characterized by two inputs: error of the controlled variable and integral of the same error. The output of the controller constitutes the manipulation variable, i.e. dilution rate. The inference method used for the type- 2 fuzzy controller is a first-order Sugeno method.
In Fig. 8 the input variables of the type- 2 fuzzy controller (error $e$ and integral of the error int $e$ ) are fuzzified as type- 2 input fuzzy sets. The input type-2 fuzzy sets are given in Eqs. (25) and (26) and are shown in Fig. 9(a) and (b). The outputs are linear functions of $e$ and int $e$ e given by Eqs. (26):

NBlower $=\exp \left(-0.5((e-0.002641) / 0.003041)^{2}\right)$

NBupper $=\exp \left(-0.5((e-0.002641) / 0.0048)^{2}\right)$ 
PBlower $=\exp \left(-0.5((e-0.07823) / 0.00278)^{2}\right)$

PBupper $=\exp \left(-0.5((e-0.07823) / 0.0058)^{2}\right)$

$\mathrm{NB}^{\prime}$ lower $=\exp \left(-0.5((\text { int } e-0.004794) / 0.088)^{2}\right)$

$\mathrm{NB}^{\prime}$ upper $=\exp \left(-0.5((\text { int } e-0.004794) / 0.09288)^{2}\right)$

$\mathrm{PB}^{\prime}$ lower $=\exp \left(-0.5((\text { int } e-0.08044) / 0.0643)^{2}\right)$

$\mathrm{PB}^{\prime}$ upper $\left.=\exp (-0.5(\text { int } e-0.08044) / 0.09943)^{2}\right)$

Output $1=28.21 e+30.98$ int $e-2.4540$

Output $2=28.16 e+30.35$ int $e-2.423$

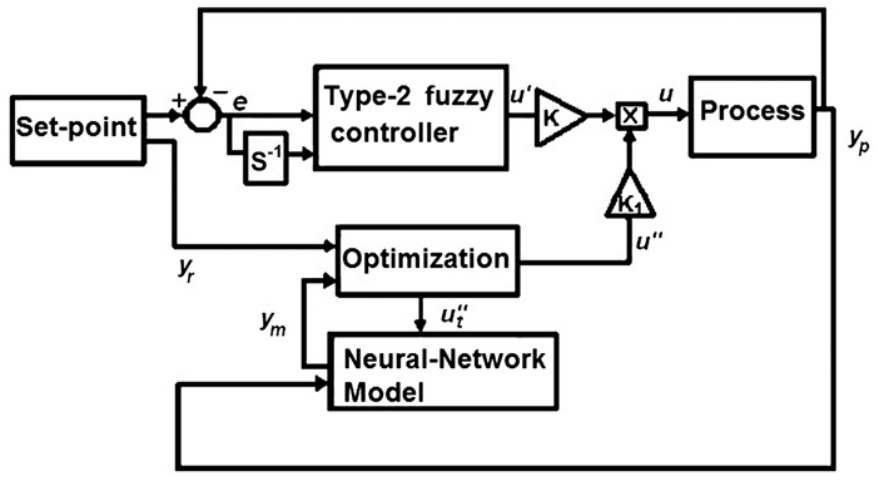

Fig. 8. Diagram block for the type-2 fuzzy neural network predictive control system.
The rules of the type- 2 fuzzy controller are as follows:

If $e$ is $\mathrm{NB}$ and int $e$ is $\mathrm{NB}^{\prime}$ then $u^{\prime}$ is Output1

If $e$ is $\mathrm{PB}$ and int $e$ is $\mathrm{PB}^{\prime}$ then $u^{\prime}$ is Output2

The output of the type- 2 fuzzy inference engine is a type- 2 fuzzy set and must be type-reduced. The centre of sets reported in Eq. (3) was used for type reduction.

In (3) $Y_{\cos }(x)$ is an interval set determined by its two end points, $y_{1}$ and $y_{\mathrm{r}}$, while $\left[f^{i}, \bar{f}^{i}\right]$ is the interval firing level of the $i$ th rule and $\left[y_{1}^{i}, y_{\mathrm{r}}^{i}\right]$ the centroid of the consequent interval type-2 fuzzy set.

Eq. (3) can be computed using the iterative method of Karnik and Mendel (2000b):

- for $i=1, \ldots, N$ set $y^{i}=y_{1}^{i}$ or $y^{i}=y_{\mathrm{r}}^{i}$;

- arrange $y^{i}$ in ascending order;

- for $i=1, \ldots, N$ set $f^{i}=f^{i}+\bar{f}^{i} / 2 ; y^{\prime}=\sum_{i=1}^{N} y^{i} f^{i} / \sum_{i=1}^{N} f^{i}$;

- do $y^{\prime \prime}=y^{\prime}$;

- find $k \in[1, N-1]$ such that $y^{k} \leq y^{\prime} \leq y^{k+1}$;

- for $i \leq k$ set $f^{i}=\bar{f}^{i}$ or $f^{i}=f^{i}$

- for $i \geq k+1$ set $f^{i}=f^{i}$ or $f^{i}=\bar{f}^{i} ; y^{\prime}=\sum_{i=1}^{N} y^{i} f^{i} / \sum_{i=1}^{N} f^{i}$;

- while $y^{\prime} \neq y^{\prime \prime} y_{1}=y^{\prime}$ or $y_{\mathrm{r}}=y^{\prime}$.

The defuzzified output $u^{\prime}$ is an interval type- 1 fuzzy set and is calculated following Eq. (4) as a simple average of $y_{1}$ and $y_{\mathrm{r}}$ :

$u^{\prime}=\frac{y_{1}+y_{\mathrm{r}}}{2}$

The output of type-2 FLC $u^{\prime}(t)$, multiplied by the scaling factor $K$, is multiplied to $K_{1} u^{\prime \prime}(t)$ and the result of the product $u(t)$ is sent to the plant (Fig. 8).

a

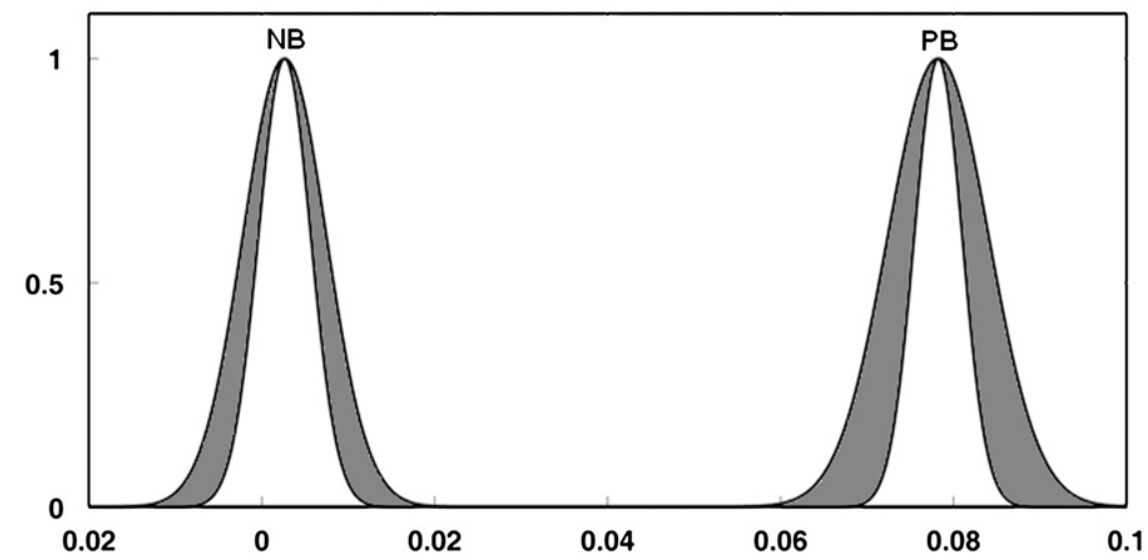

b

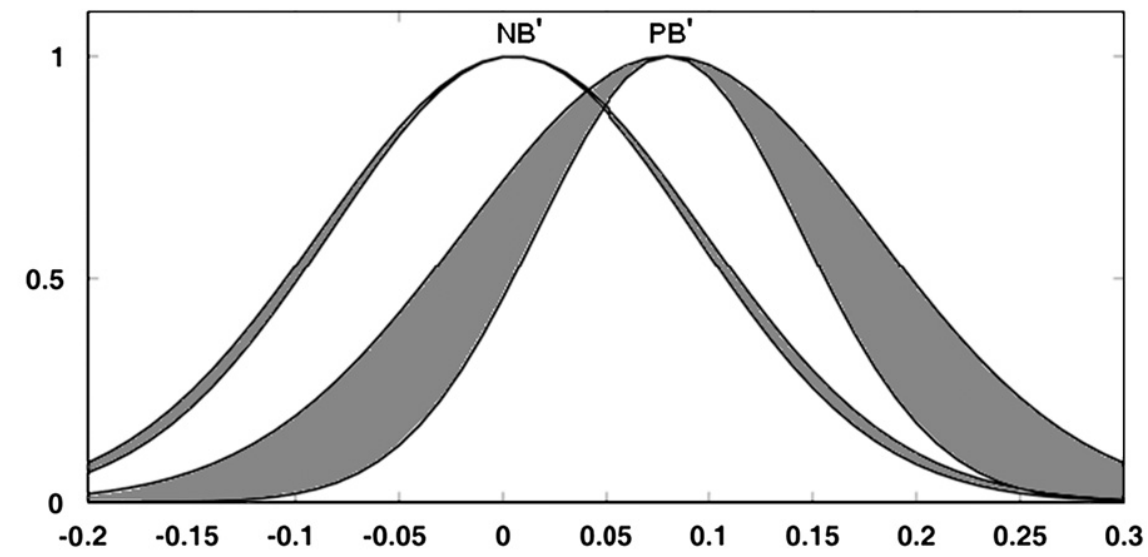

Fig. 9. Fuzzy sets for the type-2 fuzzy controller with 2 rules: (a) error (e) and (b) integral of error (int $e$ ). 


\subsection{Type-2 self-tuning fuzzy controller}

The second adaptive controller is a robust type- 2 self-tuning fuzzy controller (T2STFC). It was designed taking into account the controller proposed by Mudi and Pal (2000). In this particular adaptive mechanism, the fuzzy rules of a secondary fuzzy controller adjust online the output scaling factor (SF) of the main fuzzy controller according to the current trend of the controlled process. A type-1 fuzzy controller with a hierarchical structure based on the same scheme proposed by Mudi and Pal has been already used for the control of a bubble column that presents bifurcation (Montana Lampo et al., 2002).

The type-2 self-tuning fuzzy controller used here is characterized by a normal type- 2 fuzzy controller with 2 rules and by an adaptive mechanism constituted, as above referred, by a type- 1 fuzzy controller with 2 rules as well.

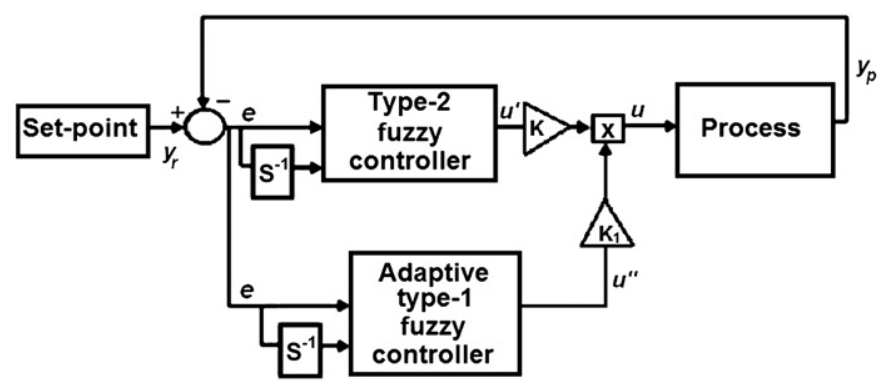

Fig. 10. Diagram block for the type-2 self-tuning fuzzy control system.
The control variable from the type- 2 fuzzy controller $u^{\prime}(t)$, multiplied by the scaling factor $K$, is updated (with the product operator) by the signal that comes from the type- 1 fuzzy controller $K_{1} u^{\prime \prime}(t)$ and then sent to the plant as $u(t)$ as shown in Fig. 10. The inputs of the two fuzzy controllers, the main and the adaptive, are in this case the error $(e)$ and the integral of the error (inte). The input type- 1 fuzzy sets of the adaptive fuzzy controller are given in Eq. (28) and shown in Fig. 11(a) and (b). The outputs are linear functions of $e$ and int $e$ given by Eq. (29).

$$
\begin{aligned}
& \mathrm{NBa}=\exp \left(-0.5((e-0.005128) / 0.01557)^{2}\right) \\
& \mathrm{PBa}=\exp \left(-0.5((e-0.03743) / 0.01316)^{2}\right) \\
& \mathrm{NBa}^{\prime}=\exp \left(-0.5((\text { int } e-0.1962) / 0.03909)^{2}\right) \\
& \mathrm{PBa}^{\prime}=\exp \left(-0.5((\text { int } e-0.01015) / 0.02933)^{2}\right)
\end{aligned}
$$

Output_a1 $=-0.0146 e+-0.01084$ int $e+1.496$

Output_a2 $=-0.001117 e+-0.002098$ int $e+1.495$

The rules of the type-2 fuzzy controller are as follows:

If $e$ is $\mathrm{NBa}$ and int $e$ is $\mathrm{PBa}^{\prime}$ then $u^{\prime}$ is Output_a1

If $e$ is $\mathrm{PBa}$ and int $e$ is $\mathrm{NBa}^{\prime}$ then $u^{\prime}$ is Output_a2

The union of traditional PI actions (proportional and integrative), type-2 fuzzy logic structure and a simple type- 1 fuzzy adaptive mechanism allows obtaining of a robust and efficient control able to handle all disturbances that normally characterize all real systems, from the simplest to the more complex.

a

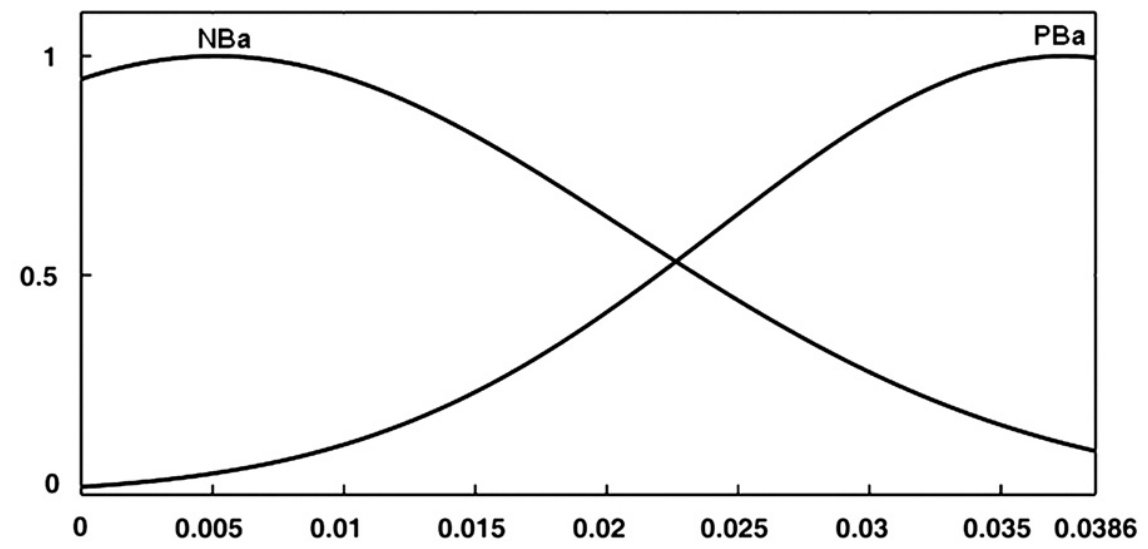

b

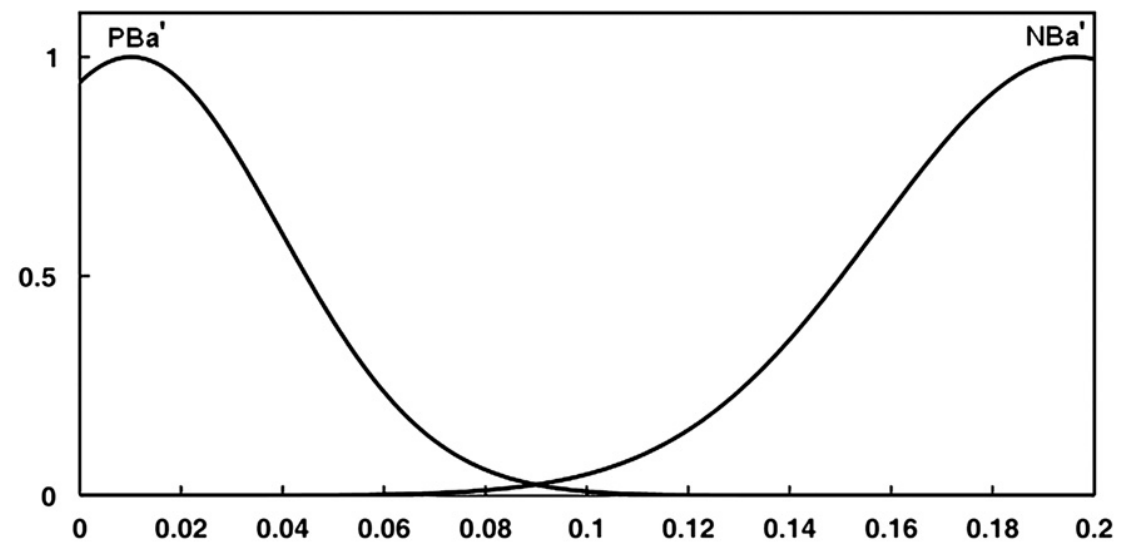

Fig. 11. Fuzzy sets for type- 1 adaptive fuzzy controller with 2 rules: (a) error and (b) integral of error. 


\section{Comparison of controller performance}

The objective of bioreactor control is to keep the system in the chosen initial equilibrium point, with glucose concentration equal to $0.065 \mathrm{gl}^{-1}$ (point $\mathrm{A}$ in Fig. 4), even in the presence of disturbances and parameter changes. The performance of the type-2 fuzzy controller with 49 rules described in Section 4 was compared by simulation with the performance of the two adaptive controllers: the T2FNPC and the T2STFC. Each adaptive type-2 fuzzy controller is characterized by a very few number of rules $(=2)$. This allows considerable decrease in computational load and makes all simulations faster, in spite of the presence of an adaptive loop, than those obtained with the non-adaptive type-2 fuzzy controller.

In Fig. 12 the simulation result obtained on disturbing the system with a negative step in $S_{\mathrm{f}}$ from 15 to $14 \mathrm{gl}^{-1}$ is shown. Each type-2 fuzzy controller leads glucose concentration to the set-point value, removing the effects of disturbance. The two adaptive fuzzy controllers perform better than the simple T2FC, with T2STFC showing the best performance. TST2FC in fact has the fastest control action and the lowest deviation amplitude after the disturbance.

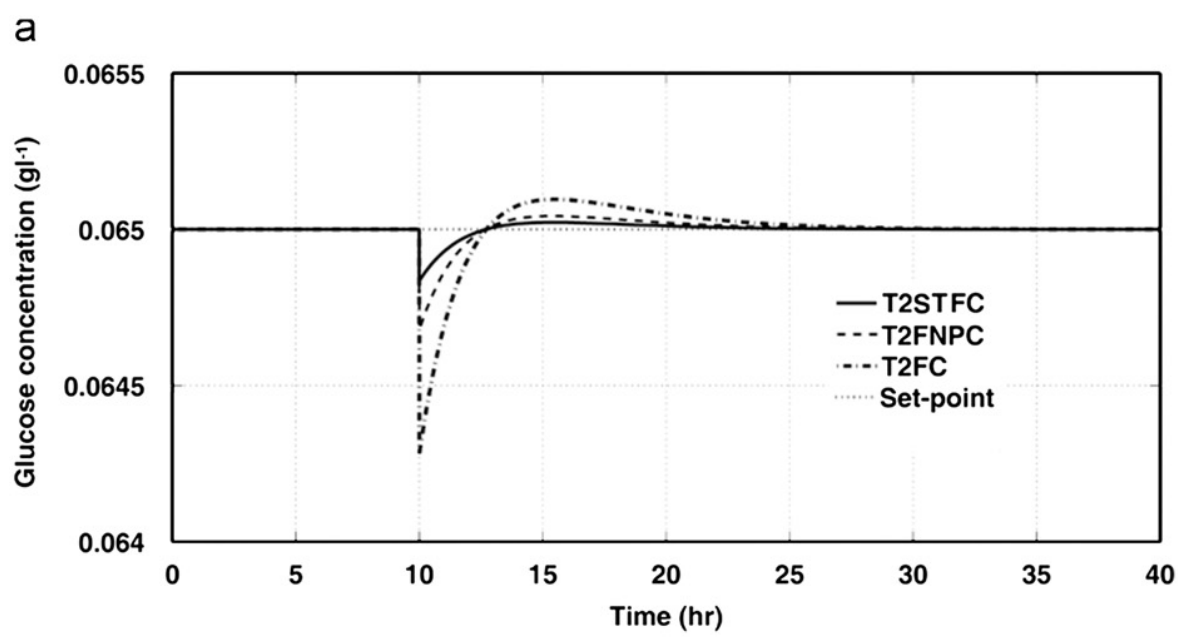

b

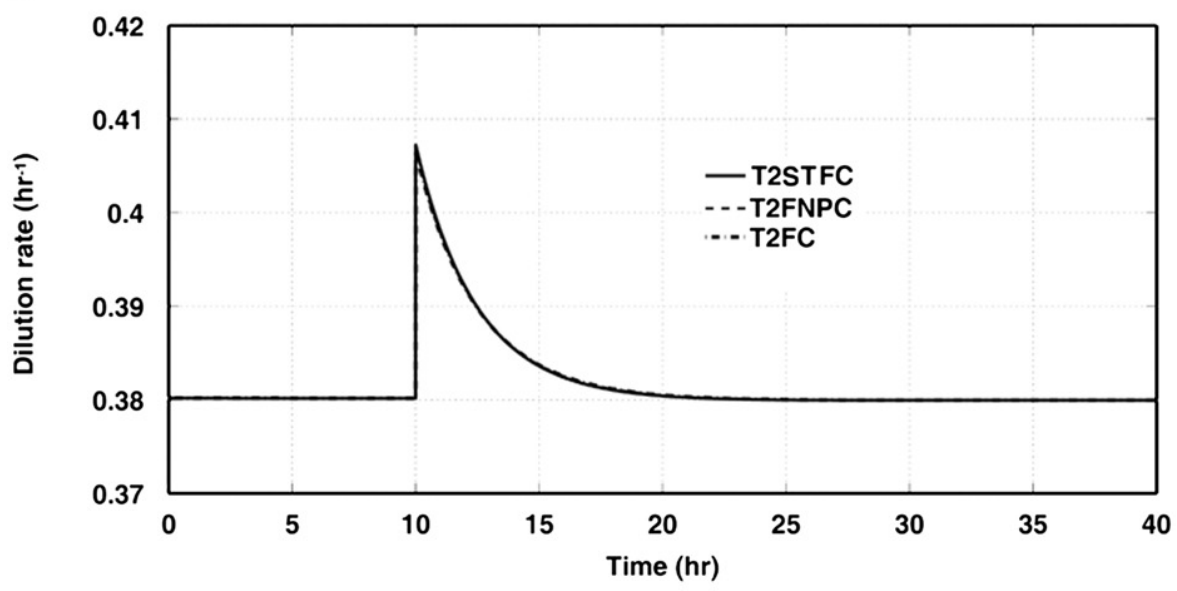

C

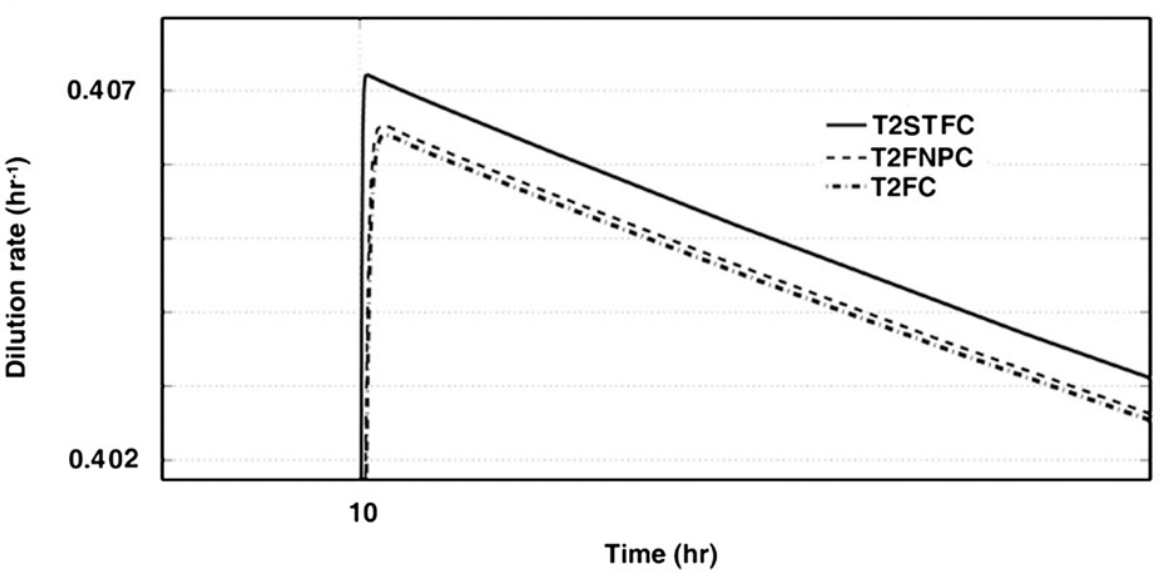

Fig. 12. Response of the controlled system to a $S_{\mathrm{f}}$ disturbance (step from 15 to $14 \mathrm{gl}^{-1}$ at $t=10 \mathrm{~h}$ ): (a) glucose concentration, (b) dilution rate and (c) zoom of (b). 
In Fig. 12(b) the manipulated variable, i.e. dilution rate, is reported. From the figure it seems that all controllers have the same manipulative variable values. In effect if a zoom of the figure is done (Fig. 12(c)) it can be observed that the manipulative variable has different trends even if they are initially very close.

In Fig. 13 the simulation results obtained on imposing a ramp disturbance to the $k_{7}$ kinetic parameter (Table 1 ), starting at $t=10 \mathrm{~h}$ and lasting until the end of simulation time with $-0.002 \mathrm{~h}^{-1}$ slope and a step disturbance to $S_{\mathrm{f}}$ (step from
15 to $14 \mathrm{gl}^{-1}$ at $t=30 \mathrm{~h}$ ) are shown. In this case all the three type- 2 fuzzy controllers are not able to remove the negative effects of $k_{7}$ parameter drift, all producing an offset, more accentuated in the case of the simple type- 2 fuzzy controller. Also in this case T2STFC minimizes in the best way effects of the kinetic parameter disturbance while the dilution rate variable shows small differences for the three cases.

The simulation results shown in Fig. 14 are concerned with a random variation of the $k_{7}$ kinetic parameter and again confirm the best behaviour of T2STFC. In this case in fact the answer of the

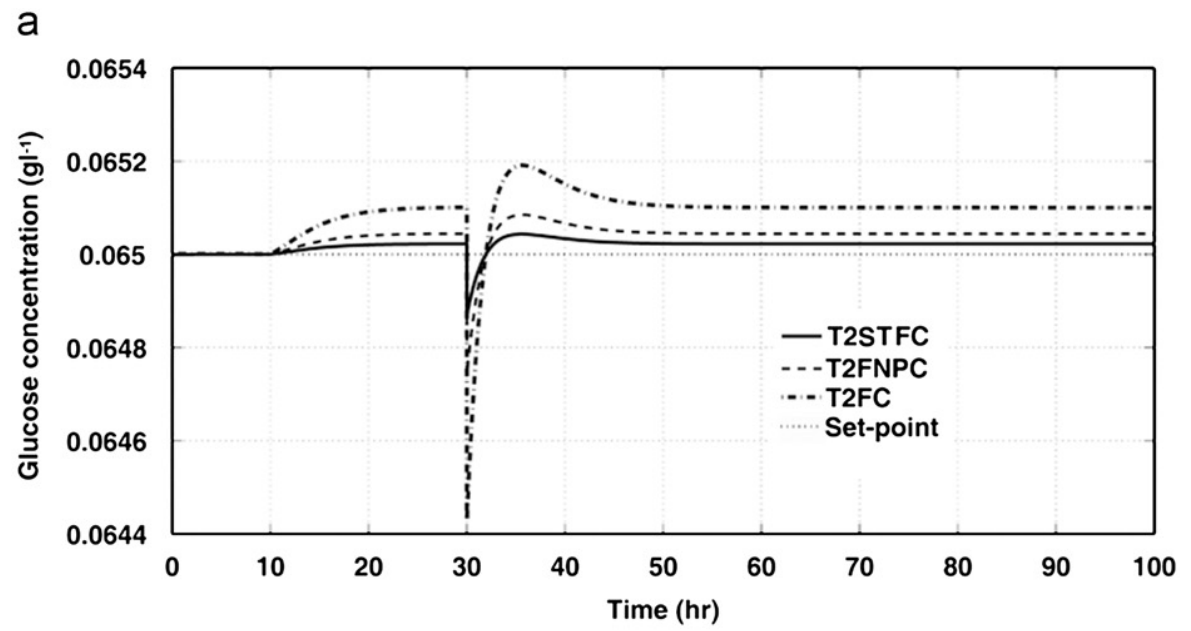

b

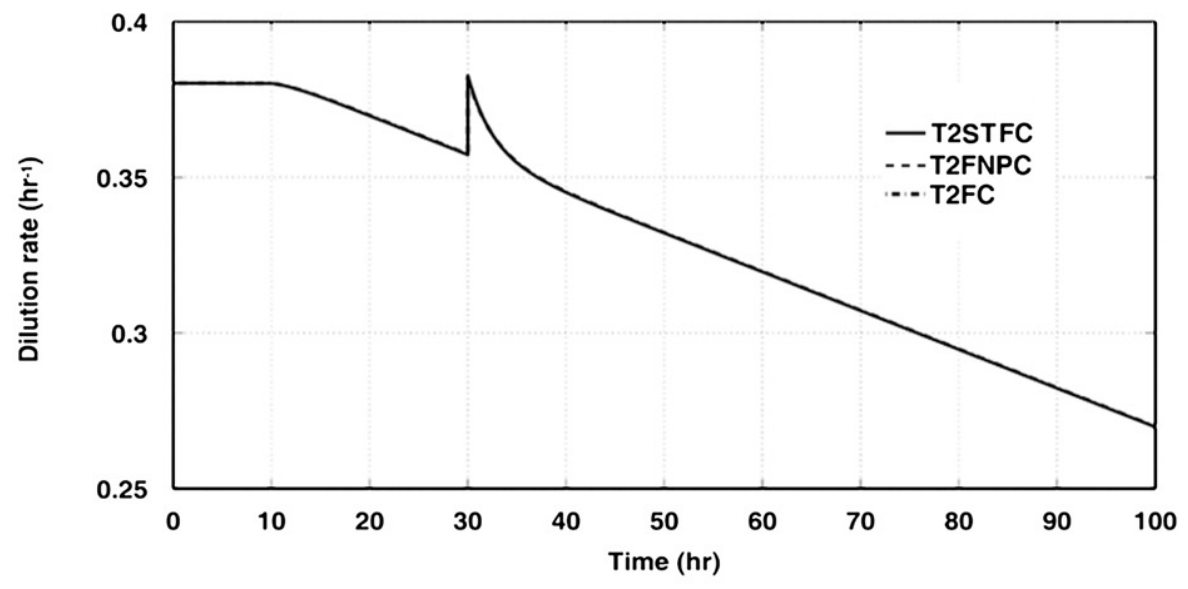

C

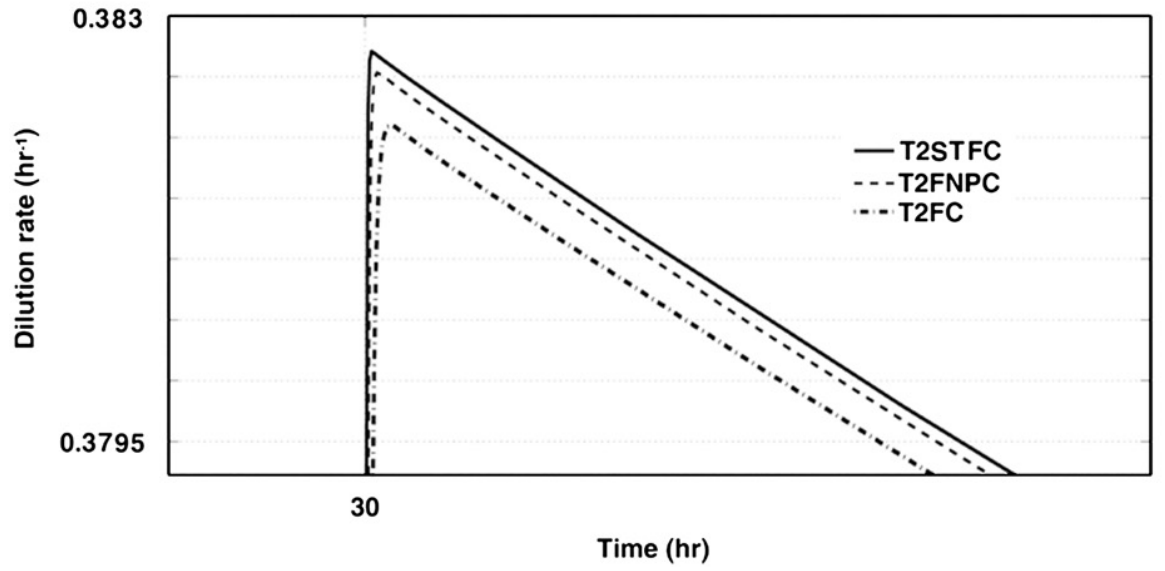

Fig. 13. Response of the controlled system to a $k_{7}$ disturbance (ramp starting at $t=10 \mathrm{~h}$ ) and to a $S_{\mathrm{f}}$ disturbance (step from 15 to $14 \mathrm{gl}^{-1}$ at $t=30 \mathrm{~h}$ ): (a) glucose concentration, (b) dilution rate and (c) zoom of (b). 
system is the fastest (Fig. 14(a)), very different from those obtained with the other two controllers (T2FNPC and T2FC).

The dynamics of the dilution rate for the bioreactor controlled by the T2STFC and T2FC are very similar (Fig. 14(b)), with some oscillations that have an amplitude value slightly larger than that of T2FNPC and a lower frequency.

In Fig. 15 the response of the bioreactor to a $S_{\mathrm{f}}$ step from 15 to $14 \mathrm{gl}^{-1}$ at $t=5 \mathrm{~h}$ is shown; a second step was imposed to $k_{7}$ from 1.203 to 1.1 at $t=25 \mathrm{~h}$; a third and a fourth step were imposed at $t=45 \mathrm{~h}$ to other two kinetic parameters: $K_{11}$ from
0.94 to $1 \mathrm{gl}^{-1}$ and $k_{3}$ from 0.501 to $0.48 \mathrm{~h}^{-1}$. Even though the simulation results in Fig. 15(b) and (c) show similar performances of the three fuzzy controllers, from Fig. 15(a) it is evident that the two adaptive fuzzy controllers outperform their nonadaptive counterpart. It seems that the change of the two kinetic parameters $k_{i 11}$ and $k_{3}$ has no effects on the bioreactor controlled by adaptive fuzzy controllers. In particular T2STFC is very fast and robust to changes of feed substrate concentration and the kinetic parameters, in comparison with the other two fuzzy controllers.

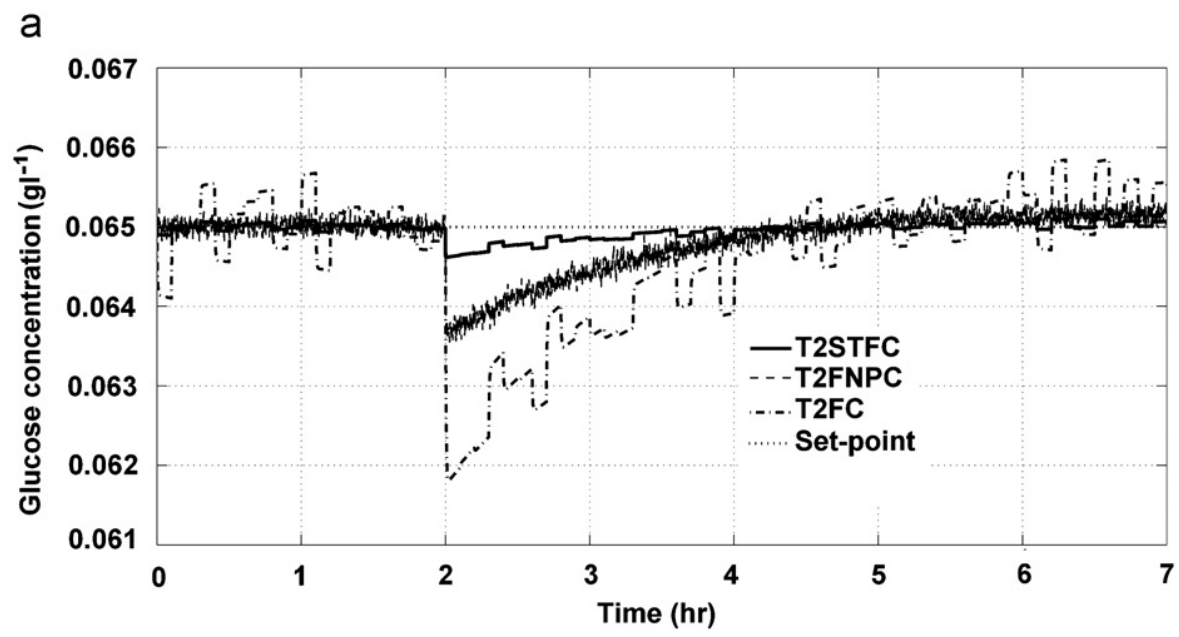

b
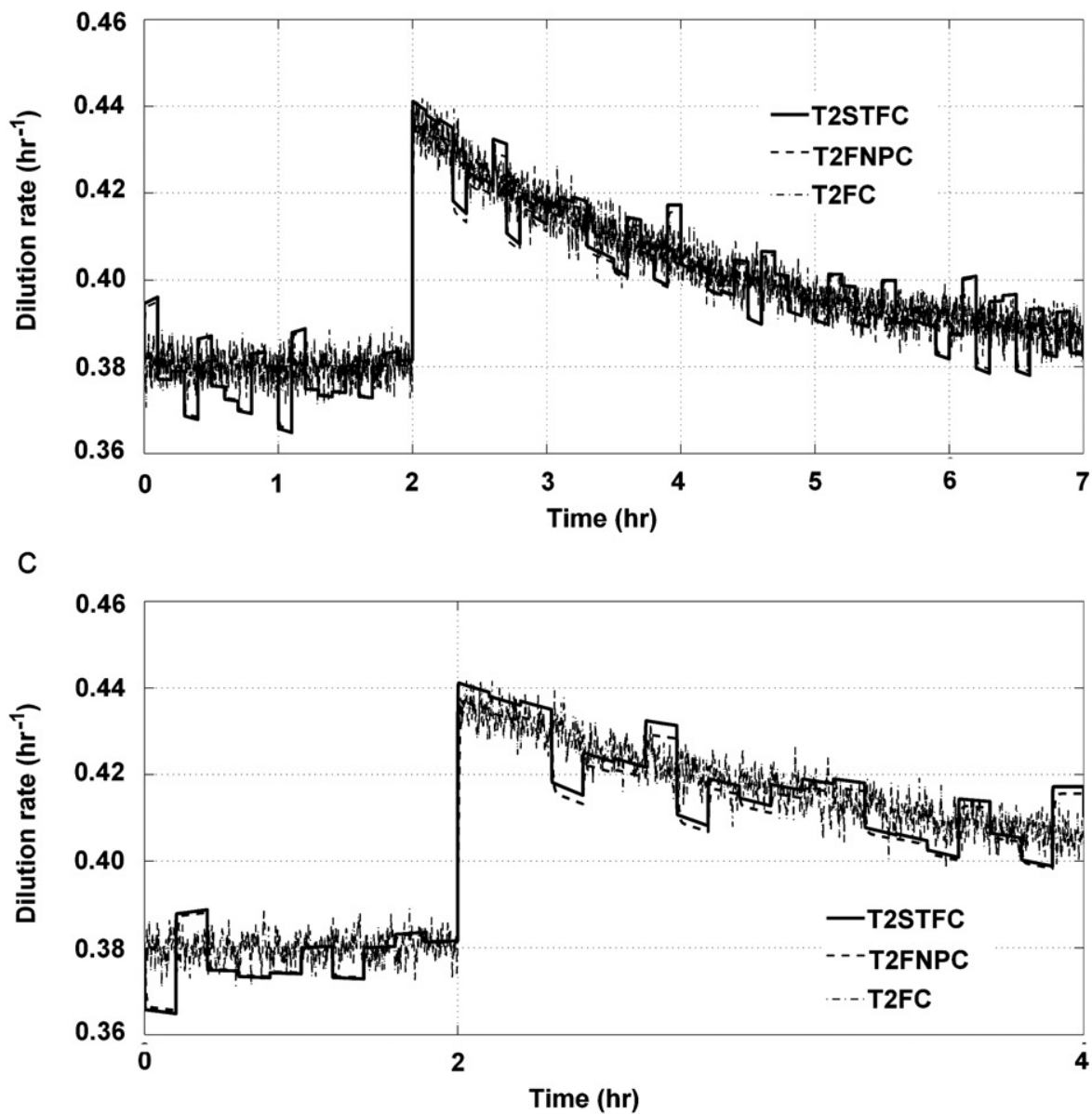

Fig. 14. Response of the controlled system to a random variation of $k_{7}$ and to a $S_{\mathrm{f} 1}$ disturbance (step from 15 to $13 \mathrm{~g} \mathrm{l}^{-1}$ at $t=2 \mathrm{~h}$ ): (a) glucose concentration, (b) dilution rate and (c) zoom of (b). 
a

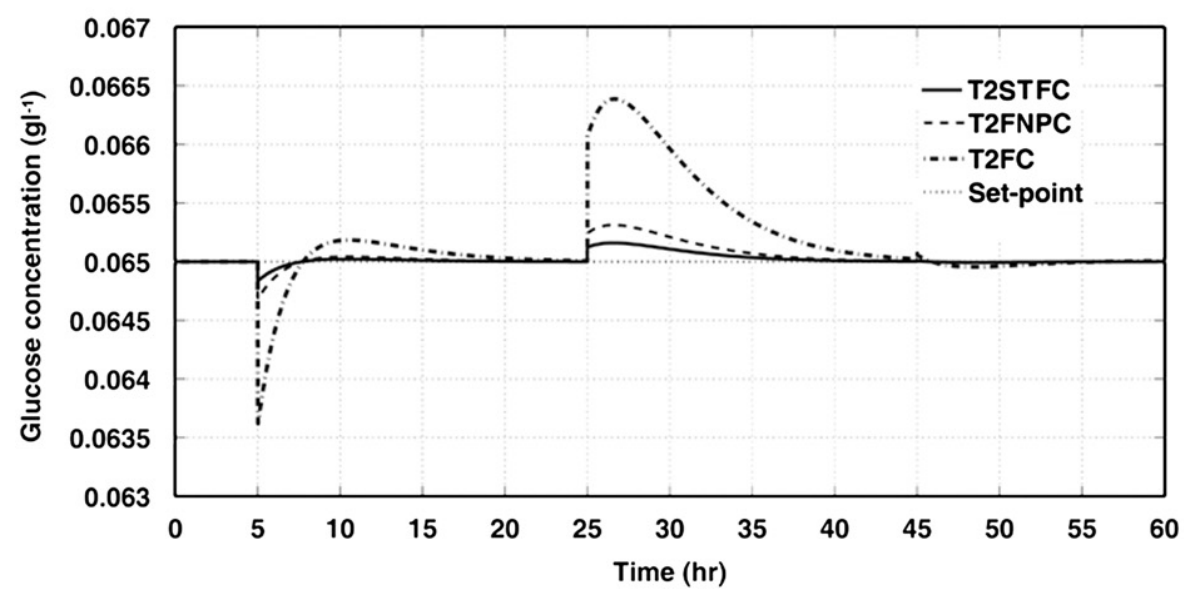

b

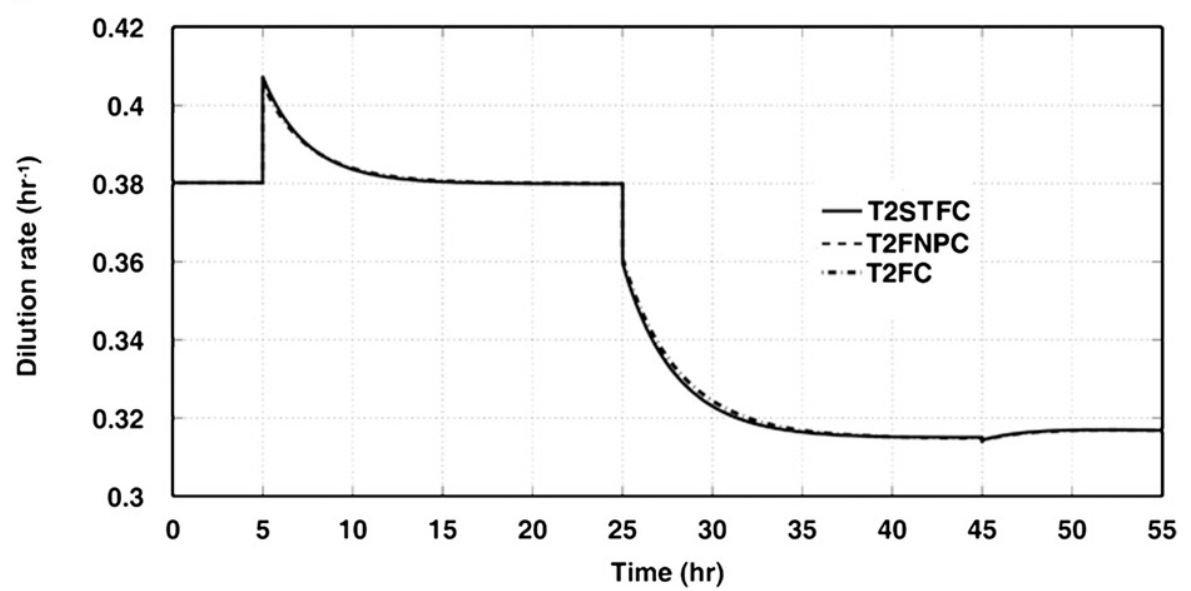

C

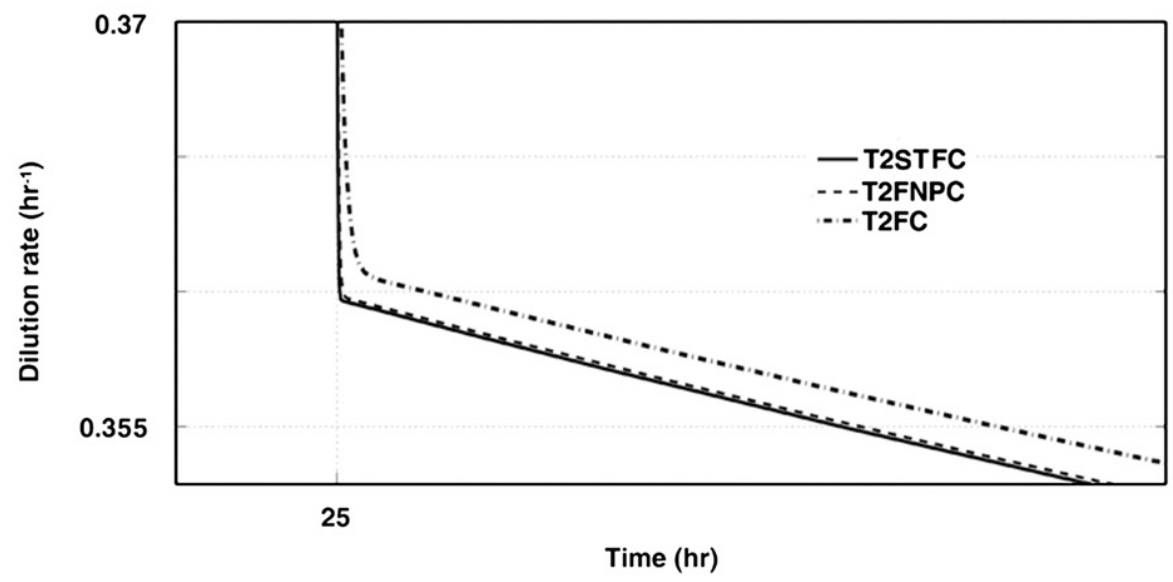

Fig. 15. Response of the controlled system to disturbances in $S_{\mathrm{f}}$ (step from 15 to $14 \mathrm{~g} \mathrm{l}^{-1}$ at $t=5 \mathrm{~h}$ ), in $k_{7}$ (step from 1.203 to 1.1 at $t=25 \mathrm{~h}$ ), in $K_{11}$ (step from 0.94 to $1 \mathrm{lg}-1$ ) and in $k_{3}$ (step from 0.501 to $0.48 \mathrm{~h}^{-1}$ at $t=45 \mathrm{~h}$ ): (a) glucose concentration, (b) dilution rate and (c) zoom of (b).

In Figs. 16-18 the unforced response of the system starting from various non-equilibrium points is reported. In all cases it is clear from the simulations that the dynamics of the control system is faster than when disturbance or parameter changes are present. In all cases both when the initial point (i.e. $s_{\mathrm{glu}}=0.063$, Fig. 14) is close to set-point value and when it is further (i.e. $s_{\text {glu }}=0.085$, Fig. $15 ; s_{\text {glu }}=0.045$, Fig. 16) the performance of STT2FC is better than that of T2FNPC and T2FC.

\section{Conclusions}

Three main conclusions can be drawn from the simulation study results:

(1) it is confirmed that the use of type-2 fuzzy logic controllers is an effective solution for control of systems characterized by parameter uncertainty; 


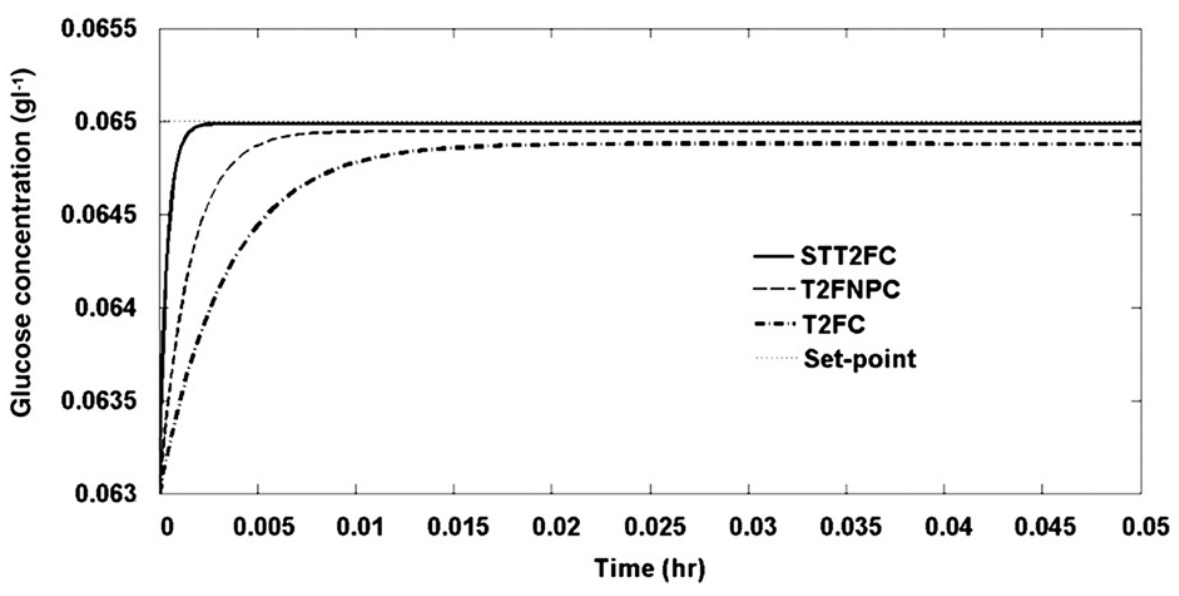

Fig. 16. Response of the controlled system starting from a non-equilibrium point $\left(s_{\mathrm{glu}}=0.063\right)$

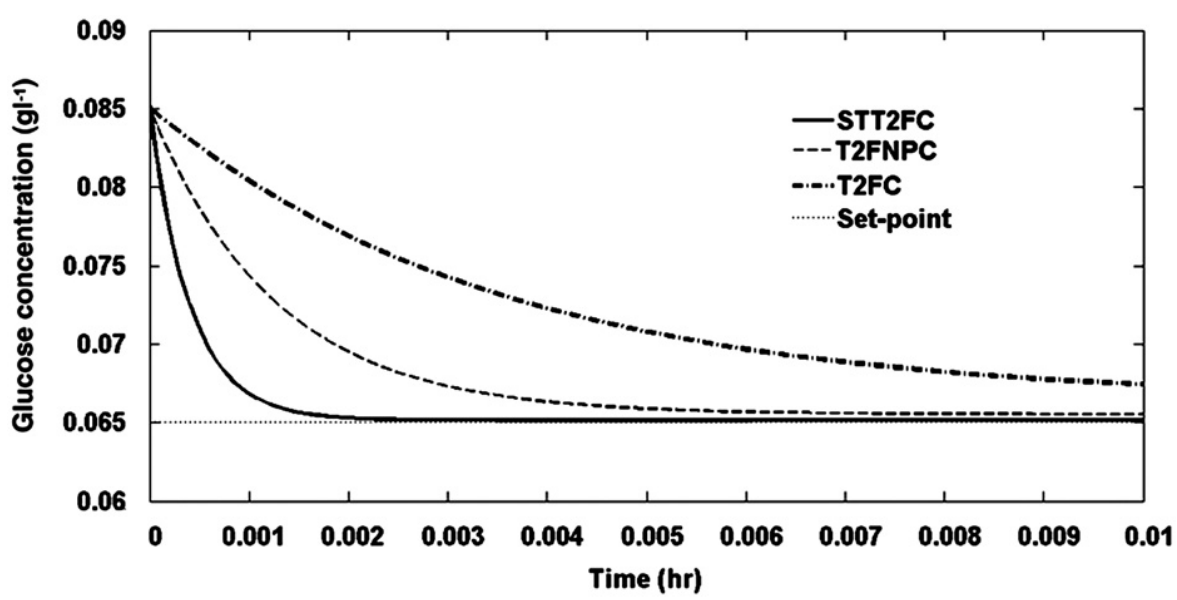

Fig. 17. Response of the controlled system starting from a non-equilibrium point $\left(s_{\mathrm{glu}}=0.085\right)$.

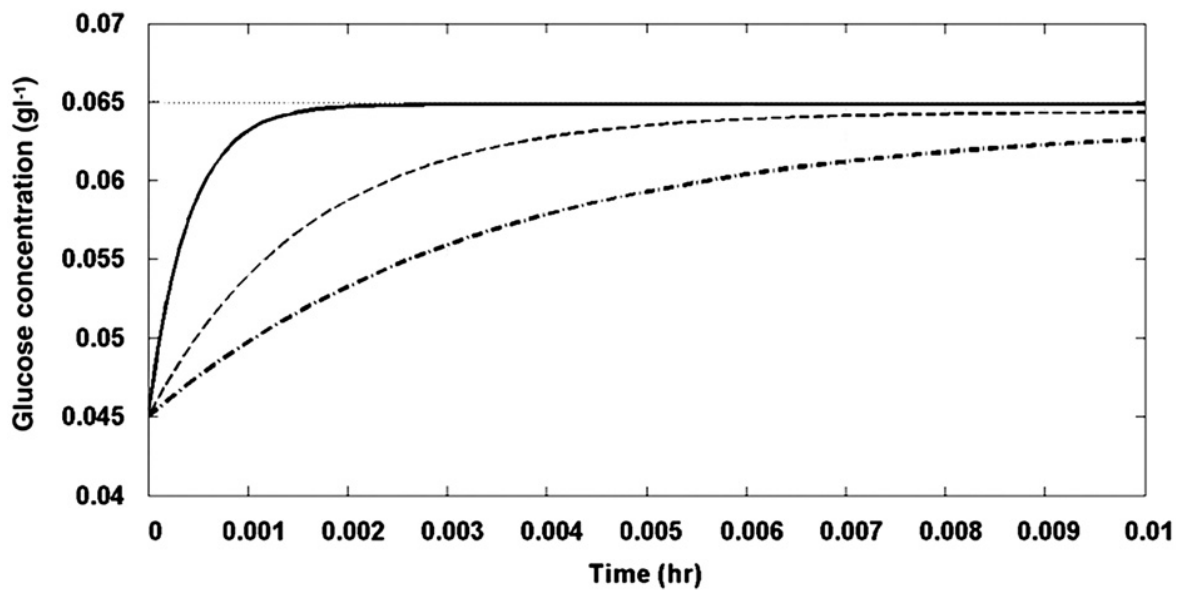

Fig. 18. Response of the controlled system starting from a non-equilibrium point $\left(s_{\mathrm{glu}}=0.045\right)$.

(2) introduction of an adaptive loop improves performance of the type-2 controller, in some cases in a significant way, and allows reduction of the number of rules and computation load;

(3) type-2 self-tuning fuzzy controller has in all cases the best performance in terms of robustness, response speed and effectiveness; the simplicity of the structure makes its implementation easy and straightforward.

\section{Nomenclature for fuzzy sets}

$\tilde{A} \quad$ type-2 fuzzy set

$F_{i} \quad$ fuzzy set in $X$ (antecedent set)

FOU footprint of uncertainty

G fuzzy set in $Y$ (consequent set)

$J_{x} \quad$ interval $\subseteq[0,1]$

$R \quad$ rule 
input variable (crisp input) output variable (crisp output) $y$ domain

$\left[f^{i}, \bar{f}^{i}\right]$ interval firing level of the $i$ th rule

$\left[\bar{Y}_{l}^{i}, Y_{r}^{i}\right] \quad$ centroid of the consequent interval type-2 set

\section{References}

Cao, J., Liu, H., Li, P., Brown, D., 2008. Adaptive fuzzy logic controller for vehicle active suspension with interval type-2 fuzzy membership functions. In: Proceedings of the IEEE FUZZ Conference, Hong Kong, China, pp. 1361-1373.

Castillo, O., Huesca, G., Valdez, F., 2005. Evolutionary computing for optimizing type-2 fuzzy systems in intelligent control of non-linear dynamic plants. In: Proceedings of the North American Fuzzy Information Processing Society, NAFIPS, Ann Arbor, MI, pp. 247-251.

Fredriksson, J., 2001. Probing control of glucose feeding in cultivation of Saccharomyces Cerevisiae. Master thesis, Lund Sweden University, Department of Automatic Control, Lund Institute of Technology.

Galluzzo, M., Cosenza, B., Matharu, A., 2008. Control of a nonlinear continuous bioreactor with bifurcation by a type-2 fuzzy logic controller. Computers and Chemical Engineering 32, 2986-2993.

Galluzzo, M., Cosenza, B., 2009. Control of the biodegradation of mixed wastes in a continuous bioreactor by a type-2 fuzzy logic controller. Computers and Chemical Engineering 33, 1475-1483.

Hagras, H., 2004. A type-2 fuzzy logic controller for autonomous mobile robots. In: Proceedings of the IEEE International Conference on Fuzzy Systems, Budapest, Hungary, pp. 965-970.

Hagras, H., 2007. Type-2 FLCs: a new generation of fuzzy controllers. IEEE Computational Intelligence Magazine 2 (1), 30-44.

Karnik, N.N., Mendel, J.M., 1998. Introduction to type-2 fuzzy logic systems. In: Proceedings of the IEEE FUZZ Conference, Anchorage, pp. 915-920.

Karnik, N.N., Mendel, J.M., 2000a. Operations on type-2 fuzzy sets. Fuzzy Sets and Systems $122,327-348$.

Karnik, N.N., Mendel, J.M., 2000b. Centroid of a type-2 fuzzy set. Information Sciences $132,195-220$.
Lei, F., Rotboll, M., Jorgensen, S.B., 2001. A biochemically structured model for Saccharomyces cerevisiae. Journal of Biotechnology 88, 205-221.

Lynch, C., Hagras, H., Callaghan, V., 2006. Using uncertainty bounds in the design of an embedded real-time type-2 neuro-fuzzy speed controller for marine diesel engines. In: Proceedings of FUZZ-IEEE. Vancouver, Canada, pp. 7217-7224.

Martinez, R., Castillo, O., Aguilar, L.T., 2008. Intelligent control for a perturbed autonomous wheeled mobile robot using type- 2 fuzzy logic and genetic algorithms. Journal of Automation, Mobile Robotics and Intelligent Systems 2 (1), 12-22.

Mendel, J.M., Liang, Q., 1999. Pictorial comparisons of type-1 and type-2 fuzzy logic systems. In: Proceedings of the IASTED International Conference on Intelligent Systems and Control, Santa Barbara, CA, pp. 280-285.

Mendel, J.M., 2002. Uncertainty, type-2 fuzzy sets, and footprints of uncertainty. In: Proceeding of the Ninth International Conference on Information Processing and Management of Uncertainty in Knowledge Based Systems, Annecy, France, pp. 325-331.

Montana Lampo, C., Bartolozzi, V., Picciotto, A., Galluzzo, M., 2002. Adaptive fuzzy control of a process with bifurcation. In: Continillo, G., Crescitelli, S., Giona, M. (Eds.), Nonlinear Dynamics and Control in Process Engineering-Recent Advances. Springer, Milan, pp. 209-223.

Mudi, R.K., Pal, N.R., 2000. A self-tuning fuzzy PI controller. Fuzzy Sets and Systems 115 (2), 327-338.

Postma, E., Verduyn, C., Scheffers, A., Van Dijken, J., 1989. Enzymatic analysis of the Crabtree Effect in glucose-limited chemostat cultures of Saccharomyces Cerevisiae. Applied and Environmental Microbiology 55, 468-477.

Preuß, K., Le Lann, M.-V., Proth, J., Pingaud, H., 2000. Modelling and predictive control of fed-batch yeast growth on industrial pilot plant scale. Chemical Engineering Journal 78, 53-59.

Sepulveda, R., Castillo, O., Melin, P., Rodríguez-Díaz, A., Montiel, O., 2007. Experimental study of intelligent controllers under uncertainty using type-1 and type-2 fuzzy logic. Information Sciences 177, 2023-2048.

Sugeno, M., 1985. Industrial Applications of Fuzzy Control. Elsevier Science Pub. Co.

Wu, D., Tan, W.W., 2004. A type-2 fuzzy logic controller for the liquid-level process. In: Proceedings of the IEEE International Conference on Fuzzy Systems, Budapest, Hungary, pp. 953-958.

Wu, D., Tan, W.W., 2006. Genetic learning and performance evaluation of interval type-2 fuzzy logic controllers. Engineering Applications of Artificial Intelligence $19(8), 829-841$.

Zadeh, L.A., 1975. The concept of a linguistic variable and its applications to approximate reasoning-1. Information Sciences 8, 199-249. 